\title{
El dominio público como presupuesto objetivo para la imposición de tributos y otros gravámenes a la actividad minera
}

THE PUBLIC DOMAIN AS THE OBJECTIVE PRESUPPOSITION FOR THE IMPOSITION OF TAXES AND OTHER BURDENS ON MINING ACTIVITY

Michelle AZUAJe PiRELA ${ }^{1}$

\section{RESUMEN}

En el ámbito de los regímenes especiales aplicados a la explotación de los recursos mineros a nivel internacional es común el uso de los términos "canon", "regalía" y "royalty", los cuales, mezclados con obligaciones de naturaleza tributaria y no tributaria, en ocasiones se emplean para hacer referencia a una serie de cantidades de dinero que deben ser pagadas normalmente al Estado, a cambio de permisos para ejercer las actividades mineras. Una de las mayores dificultades que plantea su inclusión en los ordenamientos, es la de su naturaleza jurídica: ¿Son precios públicos? ¿Son derechos? ¿Son tributos? ¿Constituyen categorías anómalas distintas de los precios públicos y los tributos? Y es que el uso de términos no integrados en la noción tripartita de tributo que los clasifica en impuestos, tasas y contribuciones, hace difícil la determinación de su verdadera naturaleza jurídica, lo que podría llevar a situaciones injustas. En todo caso, en muchas de estas figuras se halla un factor común para su exigencia: el dominio público, ese vínculo que existe entre el Estado y las minas; que pese a no ser el único criterio empleado para la imposición de gravámenes en torno a la minería sí se considera intrínseco a las actividades extractivas. El presente trabajo se propone pues, explicar por medio del análisis de algunas figuras concretas que gravan a la actividad minera en España, Perú y Chile, cómo es que el dominio público puede fungir como elemento objetivo para la exigencia de ciertos gravámenes a la actividad minera, así como la naturaleza jurídica de los mismos.

\section{PALABRAS CLAVE}

Dominio público, canon minero, regalía minera, derecho de vigencia, patente minera.

\section{ABSTRACT}

In the area of special regimes applied to the exploitation of mineral resources at the international level, it is common to use the terms "canon", "regalía" and "royalty", which, mixed with obligations of a tax and nontax nature, are sometimes used to refer to a series of amounts of money that must be paid to the State, in exchange for permits to exercise the mining activities. One of the greatest difficulties posed by its inclusion in legal systems is that of its legal nature: Are they public prices? Are they rights? Are they tributes? Are they anomalous categories other than public prices and taxes? And the use of terms not integrated into the tripartite notion of taxation, that classifies them in taxes, rates and contributions, makes it difficult to determine their true legal nature, which could lead to unfair situations. In any case, in many of these figures there is a common factor for its demand: the public domain, that link that exists between the State and the mines; although it is not the only criterion used for the imposition of taxes on mining, it is considered intrinsic

\footnotetext{
${ }^{1}$ Abogada, Universidad del Zulia. Máster en Derecho de la Empresa, Universidad de Alcalá de Henares. Doctora en Derecho, Universidad Autónoma de Chile. Profesora e Investigadora, Instituto de Investigación en Derecho, Universidad Autónoma de Chile, Chile. Correo electrónico: michelle.azuaje@uautonoma.cl. Nota aclaratoria previa: El presente trabajo presenta resultados parciales de la tesis doctoral titulada: "Fundamentos de la tributación minera: un estudio del derecho chileno a la luz del derecho español". La tesis fue redactada por la autora entre los años 2015 y 2018, bajo la tutoría de los profesores Dr. Patricio Masbernat (Universidad Autónoma de Chile) y Dr. César García Novoa (Universidad de Santiago de Compostela, España) y fue leída en diciembre de 2018. Asimismo, contó con la asesoría del profesor Michael Zavaleta Álvarez en lo relativo al ordenamiento jurídico peruano. La autora desea expresar su agradecimiento a los profesores mencionados por su amable colaboración en el desarrollo de la tesis doctoral, así como del presente trabajo.
} 
to extractive activities. The present work attempts to explain, through the analysis of some concrete figures that tax mining activity in Spain, Peru and Chile, how is it that the public domain can serve as an objective element for the demand of certain taxes on mining activity as well as their legal nature.

\section{KEYWORDS}

Public domain, mining canon, mining royalty, right of validity, mining patent

\section{Introducción}

El reconocimiento de las peculiaridades de la actividad minera ha llevado a que se incluya a las minas en la noción de dominio público o bien, a que se les considere "propiedad pública", lo que ha ocurrido por ejemplo en países como Chile ${ }^{2}$, España ${ }^{3}$ y Perú 4 . No obstante aunque como se verá, en cada uno de ellos el término dominio público o "propiedad pública" y sus implicaciones pueden ser distintas, la inserción de las minas a la categoría del dominio público las somete a regulaciones especiales, e implica también desde otro punto de vista que existen gravámenes, obligaciones y cargas, tributarias y no tributarias que adicionales al régimen general, se exigen también en función de su especialidad. Entonces, el Estado, bajo ciertos límites, puede imponer cargas a quienes se dediquen a la actividad minera, y uno de los supuestos sobre los que en este trabajo se afirma tal posibilidad, es el relativo al dominio público, término que supone una protección constitucional de ciertos bienes (en este caso las minas), y su sometimiento a un régimen especial para su aprovechamiento.

De acuerdo con las teorías funcionalistas, el dominio público (y en consecuencia el dominio público minero), alude a un conjunto de potestades, a un título de intervención que detenta el Estado para la regulación de una actividad económica compleja como es la minería, las cuales comienzan por sustraerlas de la libre apropiación de los particulares en satisfacción del interés general, lo que no es otra cosa que un acto de autoridad que implica su afectación ${ }^{5}$. Si bien, existen también teorías patrimonialistas que entienden que el dominio minero es una especie de propiedad especial del Estado, que por ese motivo goza de rasgos exorbitantes ${ }^{6}$.

\footnotetext{
${ }^{2}$ Constitución Política de Chile (CPCh), de 1980, Artículo 19 №24; Decreto Supremo № 100, de 2005; Código de Minería (CMCh), de 1983, Artículo 1; Ley N 18.248, de 1983; y Código Civil (CCCh), Artículo 591; Decreto con fuerza de Ley Número 1, de 2000 . Al respecto véase a VERGARA (1992), p. 174. También VERGARA (2001), pp. 213-216; y VERGARA (2014), pp. 633-654, quien explica la naturaleza jurídica del dominio público y para quien es irreal que exista una propiedad del Estado sobre las minas.

${ }^{3}$ La Constitución Española (CE), de 1978, establece en su artículo 132.1, que corresponde a la ley regular el régimen jurídico de los bienes de dominio público y de los comunales, debiendo inspirarse en los principios de inalienabilidad, imprescriptibilidad e inembargabilidad, así como su desafectación. Asimismo, en virtud del numeral 2 del artículo en comento, serán bienes de domin io público estatal los que determine la ley y, en todo caso, la zona marítimo-terrestre, las playas, el mar territorial y los recursos naturales de la zona económica y la plataforma continental. Según lo establece el artículo 2.1 de la Ley de Minas (LMEs), Ley N²2, de 1973, modificada por la Ley $\mathrm{N}^{\circ} 54$, de 1980, estas tienen carácter demanial, y en virtud de lo dispuesto en el artículo 3.1. ejusdem se clasifica a los yacimientos minerales y demás recursos geológicos en las siguientes secciones: A) Pertenecen a la misma los de escaso valor económico y comercialización geográficamente restringida, así como aquellos cuyo aprovechamiento único sea el de obtener fragmentos de tamaño y forma apropiados para su utilización directa en obras de infraestructura, construcción y otros usos que no exigen más operaciones que las de arranque, quebrantado y calibrado. B) Incluye, con arreglo a las definiciones que establece el Capítulo Primero del Título IV, las aguas minerales, las termales, las estructuras subterráneas y los yacimientos formados como consecuencia de operaciones reguladas por esta Ley. C) Comprende esta sección cuantos yacimientos minerales y recursos geológicos no estén incluidos en las anteriores y sean objeto de aprovechamiento conforme a esta Ley. D) Los carbones, los minerales radiactivos, los recursos geotérmicos, las rocas bituminosas y cualesquiera otros yacimientos minerales o recursos geológicos de interés energético que el Gobierno acuerde incluir en esta sección, a propuesta del Ministro de Industria y Energía, previo informe del Instituto Geológico y Minero de España.

${ }^{4}$ La Constitución Política del Perú (CPe), de 1993, establece en su artículo 66 que los recursos naturales renovables y no renovables son patrimonio de la Nación, y que el Estado es soberano en su aprovechamiento. Así lo dispone también el Título Preliminar II de la Ley General de Minería (LGM), Decreto Supremo №014-92-EM, de 1992.

${ }^{5}$ En Chile: VERGARA (1992), p. 201. En España, en esta corriente se encuentran autores como VILLAR (1964) y (1968); PAREJO (1975); PAREJO y RODRÍGUEZ (1976); GALLEGO (1982) y (1986); PAREJO (1983); GONZÁLEZ (1998) y ROSA (2009), pp. 341-390.

${ }^{6}$ La obra de Hauriou desarrollada en Francia en torno a la naturaleza jurídica del dominio público, influenció a buena parte de los autores españoles en el área, PAREJO (2011), pp. 892 y 893. De acuerdo a su concepción clásica el dominio público sería la propiedad de la Administración Pública que ha sido afectada formalmente a una finalidad pública y sujeta por tanto a un régimen especial. Siendo esta corriente la de apoyo mayoritario lo cual incide por supuesto en la noción del sistema dominial minero. En ese sentido, léase en España a ÁLVAREZ-GENDín (1956), pp. 259-302; GUAITA (1956), pp. 121-140 y (1986); GARCÍA (1984-1985) y (1998); GARCÍA y ESCALANTE (1982); GARRIDO (1962) y (2002).
} 
Ahora bien, a pesar de ello, desde el punto de vista dogmático lo cierto es que sea que se entienda como dominio-potestad 0 dominio-propiedad ${ }^{7}$, incluso las concepciones patrimonialistas no excluyen la posibilidad de reconocer y aplicar reglas exorbitantes a los bienes de dominio público, en razón de su afectación a la satisfacción del interés público, del bien común o el fomento de la riqueza nacional. Esto quiere decir que, aunque se afirme que el Estado puede ser titular en propiedad civil ordinaria de ciertos bienes, la doctrina está consciente de que una de las más importantes consecuencias de someter a ciertas categorías de bienes al dominio público, es que su régimen jurídico supondrá una o varias excepciones tanto teóricas como prácticas a lo que podría llamarse la propiedad ordinaria o propiedad civil.

Una forma muy ilustrativa de entender al dominio público en el contexto de la minería es imaginar que este funciona como una especie de cordón umbilical entre el Estado y las minas que no se rompe. Incluso si estas son aprovechadas por los particulares a través de los mecanismos que se dispongan en cada ordenamiento jurídico (normalmente por medio de una concesión), ello será así en tanto y en cuanto se contemplen causales de caducidad o pérdida del título. De ahí que el Estado no se desprende totalmente de dicho vínculo.

Que las minas integren el dominio público, supone (al menos desde el punto de vista científico) que su aprovechamiento por los particulares, quienes se harán titulares de derechos mineros beneficiándose de los mismos, debería ser jurídicamente justificado y no debería hacerse a título gratuito, porque detrás del dominio público hay un interés general que debe ser garantizado. Así se ha aceptado que dicha operación implique el establecimiento de algunas cargas.

De esta forma, de cara al proceso de reforma tributaria que se vive en Chile, resulta de interés la revisión de las bases tradicionales de la tributación minera y la forma en la que ella ha sido entendida en el ordenamiento chileno, pues siendo un país minero la revisión del sistema tributario debería tener en cuenta las particularidades y oportunidades de tributación que esta actividad económica ofrece.

Así, desde el punto de vista tributario, el dominio público minero sirve como punto de partida para explicar algunos tipos de tributos que pueden establecerse en virtud del aprovechamiento de los derechos mineros que hagan los particulares. No obstante se aclara que, aunque se le relaciona frecuentemente con las actividades extractivas, el dominio público no es el único criterio que pueda aplicarse para gravar a la actividad minera; tampoco es exclusivo ni excluyente frente a otras cargas que puedan imponerse a la misma, sobre todo si se tiene en cuenta que nada impide que el legislador configure varios hechos imponibles sobre un mismo objeto, así por ejemplo en el contexto de la minería, pueden existir además otras figuras tales como impuestos a la renta o tributos ambientales. En este trabajo, solo se hará referencia al dominio público y no a la renta y los tributos medioambientales, por exceder estos últimos al propósito del mismo.

\footnotetext{
${ }^{7}$ En Chile los autores han estado divididos cuando se trata de explicar qué es lo que debe entenderse por dominio minero y cuál es la naturaleza del que ha sido declarado por la Constitución Política. En la escasa bibliografía sobre el tema, algunos autores lo entienden como una expresión del derecho de propiedad; dentro de esta corriente, RODRÍGUEZ (1992), p. 57. Asimismo, aunque no la comparte MORILLO-VELARDE (1992), pp. 19 y 20, explica que esas posiciones han estado influenciadas por lo que en la doctrina española se habría calificado como una forma de propiedad especial o "propiedad modulada", como característica del dominio público. Otros autores lo entienden como una forma de potestades públicas; ENOS (2005), p. 121, considera que resulta "más convincente" entender al dominio público dentro de las potestades públicas. MORILLO-VELARDE (1992), p. 97, opina que el dominio público es una titularidad que ampara una pluralidad de potestades públicas de diverso alcance y funcionalidad, siendo la afectación el supuesto o título de tales potestades públicas. Denominada concepción "funcionalista", vinculada a las funciones o potesta des del Estado, "muy cercana" a la opinión de VERGARA (1990), pp. 142 y ss. También hay quienes entienden que su naturaleza es "virtual o eminente", CLARO (1979), pp. 262 y 537 y ss. Como expresan ALESSANDRI y SOMARRIVA (1974), pp. 104 y 105, el principio del dominio eminente era seguido en Chile hasta la reforma constitucional de 1971. VERGARA (1992), pp. 234, explica que esta opinión fue seguida casi unánimemente por los autores chilenos civilistas y de derecho minero, de forma acrítica y si más explicación que sus propias afirmaciones. En ese sentido, cita la opinión de Ruiz, uno de los autores que más prestigio en el derecho minero chileno, quien pensaba, en 1949, que, a pesar del claro tenor literal del art. 591 del CC (y que reproduciría el art. 1 del Código de Minería de la época), según él, en virtud de seguirse en Chile el llamado "sistema de libertad de minas", el Estado tiene sobre las minas "una propiedad eminente" virtual que solo lo faculta para otorgar los más amplios derechos a aquellos que han cumplido con requisitos legales especiales". Y finalmente, están otros para los que es "mixta," e incluso "sui generis": PRECHT (1983), p. 742; y VILDÓSOLA (1999), p. 347. OSSA (2012), p. 72. LIRA (2012), p. 40, lo catalogan como dominio público especial.
} 
Entonces, partiendo de la base de que sobre los bienes del dominio público minero pueden establecerse algunos gravámenes ${ }^{8}$, y que esta noción puede integrar el objeto del hecho imponible de algunos tributos, lo siguiente sería preguntarse en definitiva: ¿por qué? ¿Cuáles son los límites? ¿Es la sola existencia del dominio público lo que justificaría una exacción? 0 más bien, ¿Existe alguna actuación del Estado -Administración- que la justifique?, ¿cuáles son esas exacciones y cuál es su naturaleza jurídica?, ¿son tributos? ¿Deberían serlo? ¿Son figuras anómalas? ¿Estas recaen sobre alguna manifestación directa o indirecta de capacidad económica? $\mathrm{Y}$, finalmente ¿es posible encontrar alguna de estas figuras en el ordenamiento jurídico chileno?

En este orden de ideas, el Artículo $19 \mathrm{~N}^{\circ} 20$ de la CPCh dispone que "la Constitución asegura a todas las personas: 20 ․ La igual repartición de los tributos en proporción a las rentas o en la progresión o forma que fije la ley, y la igual repartición de las demás cargas públicas. También que en ningún caso la ley podrá establecer tributos manifiestamente desproporcionados o injustos [...]". Esta norma viene a suponer que en Chile se ha constitucionalizado también el marco para el ejercicio del poder tributario, basado en el principio de igualdad para contribuir a los gastos públicos como criterio de distribución. Pero este criterio de acuerdo con la jurisprudencia chilena, no ha de ser solo una igualdad formal, sino que debe incluir elementos materiales ${ }^{9}$ (por ejemplo, la no confiscatoriedad que fijará el legislador entre los varios existentes en la doctrina económica, esto es: capacidad económica, origen de rentas, beneficio del contribuyente y otros); así que se considera que es esencia de la norma tributaria gravar de acuerdo con la capacidad económica. En ese sentido, a pesar del escaso desarrollo doctrinal de los principios tributarios en Chile, la noción de capacidad económica puede entenderse como una idea de la orientación que puede seguir el legislador a la hora de establecer tributos, pues con ello responde a una idea de justicia ${ }^{10}$.

De acuerdo con esas consideraciones, en principio y con carácter general, los tributos al configurar el hecho imponible deberían incorporar en su estructura alguna manifestación de capacidad económica o elemento equivalente que sirva de objeto al mismo y que justifique una eventual exacción (por ejemplo, la renta o el patrimonio). Pero entonces, ¿cómo es que se afirma que existen tributos fundados en el dominio público? ¿Se tiene en cuenta en la estructura de ellos alguna manifestación de capacidad económica?

El presente trabajo se propone pues, explicar por medio del análisis de algunas figuras concretas que gravan a la actividad minera en España, Perú y Chile, cómo es que el dominio público puede fungir como presupuesto objetivo para la exigencia de gravámenes a la actividad minera.

\footnotetext{
${ }^{8} \mathrm{~A}$ este respecto sobre la tributación de los bienes de dominio público en el derecho español, se recomienda la lectura de GALÁN (2009), pp. 337 y ss.

${ }^{9}$ Siguiendo lo expresado por MASBERNAT (2013), pp. 156 y 157, aunque en el derecho chileno, es escasa la doctrina que se ha abocado al estudio de los principios tributarios materiales, por el contrario, sí se han enfatizado los análisis de los principios de carácter propiamente formal (reserva de ley bajo la denominación de principio de legalidad, irretroactividad de las sanciones, seguridad jurídica, etc.), del principio de igualdad ante la ley (también en un sentido formal, como idea expresiva de la no discriminación arbitraria y en gran medida análoga al principio de generalidad), y de los derechos de propiedad y libre empresa como límites de la potestad tributaria (bajo la idea de no confiscatoriedad y prohibición de tributos manifiestamente desproporcionados e injustos). Por otra parte, a pesar de esa escasa atención de los autores (en efecto, el citado es el autor que más trabajos ha dedicado al estudio de los principios tributarios en Chile), la jurisprudencia del Tribunal Constitucional da cuenta de que los abogados defienden cada vez más causas sobre la base de los principios materiales de la tributación, instando a un debate sobre ellos en el foro; pero es claro el déficit dogmático. Respecto a los principios tributarios en Chile véase también a FERMANDOIS (2010); NAVARRO (2008), pp. 81 y ss.; RIBERA (2000), p. 24 y GUERRERO (1998).

${ }^{10}$ En Chile no existe aún una línea jurisprudencial consolidada acerca de la preponderancia del principio de capacidad económica sobre otros principios de distribución de la carga tributaria a la hora de hacer efectivo el principio de igualdad material en el ámbito tributario. A diferencia de lo que ocurre en España, donde se establece expresamente que el principio de justicia en el sistema tributario se hace efectivo si se contribuye de acuerdo con la capacidad económica que da contenido al principio de igualdad y se entiende de acuerdo con un principio de progresividad. FERNÁNDEZ y MASBERNAT (2011), p. 590.
} 


\section{Los cánones y las regalías mineras en general. El problema de su naturaleza jurídica}

En el ámbito de los regímenes especiales aplicados a la explotación de los recursos mineros, es frecuente y de larga data el uso de los términos "canon" y "regalía," para referirse a una serie de cantidades de dinero que deben ser pagadas generalmente al Estado, o bien a los propietarios de ciertos derechos, a cambio de permisos para ejercerlos. Una de las mayores dificultades que plantean estas figuras es la de su naturaleza jurídica: ¿Son precios públicos? ¿Son tributos? ¿Constituyen categorías distintas de los precios públicos y los tributos? Y es que, también se les presenta como prestaciones debidas por mandato de una ley a un ente público, pero ni el término canon ni el de regalía se encuentran integrados en la noción tripartita de tributo que los clasifica en impuestos, tasas y contribuciones.

De tal suerte que en principio, serán tributos en la medida en que sus características se correspondan con las de un impuesto, tasa o contribución especial, o alguna especie reconocida como tributo en el ordenamiento jurídico respectivo. En todo caso, con independencia del alcance diferenciado que puedan tener según el país determinado, puede decirse con propiedad que el término canon es intrínseco a las industrias extractivas.

En efecto, de acuerdo con el Diccionario de la Real Academia Española, los cánones en sus acepciones octava y novena son cantidades periódicas pagadas a la Administración por el titular de una concesión demanial, o bien, específicamente en el ámbito de la minería, prestaciones pecuniarias periódicas que gravan una concesión gubernativa con disfrute en el dominio público, regulado según el número de pertenencias o de hectáreas, sean o no explotadas.

Asimismo, conforme a la décima acepción, los cánones pueden ser también percepciones pecuniarias convenidas o estatuidas para cada unidad métrica que se extraiga de un yacimiento o que sea objeto de otra percepción mercantil o industrial, como embarque, lavado, calcinación, etc.

Por su parte, a las regalías (provenientes del anglicismo royalty o royalties) se les define en su quinta acepción como participaciones en los ingresos o cantidad fija que se paga al propietario de un derecho a cambio del permiso para ejercerlo. Extendiendo esta definición a la actividad minera, la palabra regalía o royalty, haría referencia a pagos, derechos o contraprestaciones que se hacen al propietario, a cambio del derecho de extraer las sustancias minerales para su propio beneficio. Lo cual puede establecerse por vía contractual o mediante ley.

Para algunos autores ${ }^{11}$ una regalía minera, es por definición, el pago que se hace al titular de los derechos mineros cuando se extraen minerales de la tierra y son vendidos en los mercados. En tanto que en aquellos casos en los que el sistema legal de un país no permite la propiedad privada de las minas, las regalías mineras serán, por defecto, pagaderas al Estado. No obstante, en algunos casos la base legal para una regalía pagada al Estado, es la obtención de un derecho continuo a la mina, sin propiedad minera real o implícita por parte de este ${ }^{12}$.

Sin embargo, lo cierto es que, desde la perspectiva del Estado, es frecuente observar que el pago de regalías se ha impuesto en países en los que el dominio de las sustancias minerales está en manos de este con carácter patrimonialista y se otorga a los particulares la concesión para explotarlos ${ }^{13}$. En ese contexto, existen obligaciones en cabeza de las personas naturales 0 jurídicas dedicadas a la extracción de minerales, pagaderas a favor del Estado, generalmente en función de cantidades o ad valorem del mineral extraído.

Este alcance de término regalía se corresponde con el que se aplica en el ámbito de las ciencias económicas, donde se entiende que en razón de dicha entrega a los particulares y dado el carácter no renovable de los recursos mineros, el Estado debería recibir una compensación más allá de los impuestos normales pagados por otras industrias, pues los minerales que son

\footnotetext{
${ }^{11}$ CAWOOD Y MACFARLANE (2003), p. 214.

${ }^{12}$ CAWOOD (2004).

${ }^{13}$ DEUTSCH y ORELLANA (2014), p. 30.
} 
explotados hoy, no estarán disponibles para las generaciones del futuro ${ }^{14}$. Por otra parte, no debe perderse de vista que el hecho que el Estado tenga o no el dominio originario de los yacimientos minerales y en función de ello perciba las regalías, no se opone necesariamente a la creación de impuestos a la extracción de recursos naturales ${ }^{15}$. En todo caso, desde este punto de vista económico, en estricto rigor, la regalía o royalty, no es un tributo.

Pero, según explica Jarach, jurídicamente hablando, esto puede no ser así en todos los casos, ya que si bien en ocasiones las regalías mineras han llegado a considerarse un recurso originario del Estado, existen matices. Es posible observar también la gradualidad con que en los recursos públicos se pasa de los recursos patrimoniales a los tributarios, resultando imposible a veces trazar con exactitud una línea divisoria de validez absoluta entre las dos categorías de recursos ${ }^{16}$. En ese sentido, para De Arcenegui la adopción de un sistema dominial implica que debe tenerse una concepción publicista de la riqueza minera que lleve su regulación al ámbito del Derecho Administrativo, lo que para él supone también la transformación de la Hacienda Patrimonialista del antiguo régimen, en la que el Monarca se nutría de los rendimientos de determinadas categorías de bienes, como las minas con sus regalías, en una Hacienda Tributaria en la que los ingresos del Estado pasan de ser patrimoniales a provenir de la imposición ${ }^{17}$.

En definitiva, decantarse por una u otra posición dependerá del contexto, porque la realidad es que en la actividad minera, el uso indiscriminado del término regalía conlleva a la dificultad de que puede llegar a ser entendido en al menos dos acepciones ${ }^{18}$, la descrita como un derecho, compensación o recurso originario, como ocurre en Perú ${ }^{19}$; y también la de un tributo, como ocurre en países como Australia y Canadá, en los que bajo el término "royalty tax" se agrupa a diversos tributos que en distintos niveles son aplicables a la minería ${ }^{20}$; y en Chile, donde al Impuesto Específico a la Minería, que es sin duda un tributo, frecuentemente se le denomina "royalty"21.

\section{Algunos tributos y otros derechos basados en el dominio público en el derecho nacional y}

\section{comparado}

\subsection{El canon de superficie de minas en el derecho español. Elementos esenciales}

En relación al dominio público con carácter general, en el ordenamiento jurídico español, su utilización o aprovechamiento especial (que en primer lugar, requiere algún mecanismo de autorización de la Administración titular del mismo), ha dado lugar al pago de una tasa ${ }^{22}$.

\footnotetext{
${ }^{14}$ OTTO et al. (2006), p. 19.

${ }^{15}$ GARCÍA (2004), p. 249.

${ }^{16}$ JARACH (2003), p. 250.

17 DE ARCENEGUI (2002), p. 47.

18 DEUTSCH y ORELLANA (2014), p. 6.

19 Para ZUZUNAGA (2011), en Perú, la regalía minera comparte la naturaleza de un ingreso público distinto a un tributo, que en ese caso compensa la pérdida paulatina del recurso y que paga un particular a favor del Estado, con la finalidad de que se le permita el aprovechamiento del recurso mineral. El Tribunal Constitucional Peruano por su parte, en Sentencia del Pleno Jurisdiccional (Tribunal Constitucional, Número 0048-2004-PI-TC, de 1 de abril de 2005), definió a la regalía minera creada en particular por la Ley № 28.258, de 2004, como una obligación legal consistente en la contraprestación del titular de la concesión minera a los gobiernos regionales y locales por la explotación de recursos naturales, justificada en la necesidad de la nación de recibir beneficios de sus propios recursos antes que se agoten.

20 En Australia véase a GUJ (2012); quien habla de "regalías mineras y otros impuestos específicos a la minería". También OTTO et al. (2006), p. 85.

${ }^{21} \mathrm{Al}$ respecto se recomienda el estudio filológico sobre lo que significan los términos canon, regalía y royalty en el español de Chile, SÁEZ-GODOY (2006), pp. 251-265.

22 Aunque las exacciones al uso o aprovechamiento del dominio público han sido objeto de amplio debate a nivel jurisprudencial, sobre todo por lo relativo a su naturaleza jurídica: ¿son precios públicos? ¿son tasas? En ese sentido, si bien la Ley General Tributaria, de 1963, establecía en su artículo 26 su carácter de tasa y en consecuencia su naturaleza tributaria, más tarde la Ley № 8, de 1989, la integró en la categoría de precios públicos. Esta situación provocó la solicitud de impugnación por inconstitucionalidad de los artículos 1, 3.4, 24, 25, 26, 27, Disposición adicional segunda y Disposición adicional quinta de la Ley № 8, de 1989, por considerar que su contenido violaba la reserva de ley. El Tribunal Constitucional Español, sentencia № 185/1995, de 14 de diciembre de 1995, resolvió que: "Los bienes que componen el demanio son de titularidad de los Entes públicos territoriales y su utilización privativa o su aprovechamiento especial están supeditados a la obtención de una concesión o una autorización que corresponde otorgar
} 
La exigencia de la tasa (que puede ser estatal, autonómica o local según corresponda), puede encontrar su fundamento en una actividad de la Administración, esto es, la autorización especial del uso del dominio público, en la efectiva prestación de un servicio público, o bien, en el coste del servicio o el importe presunto del beneficio que se obtiene por la cesión de la utilización del dominio público en el caso de las concesiones demaniales ${ }^{23}$.

En ese sentido, el carácter demanial de las minas y el trato diferenciado que establece la ley a las diversas categorías de recursos minerales a los que separa por secciones, significan que sus formas de aprovechamiento son distintas. También que para los recursos que integran las secciones $C$ y $D^{24}$, los cuales serán aprovechados previos Permisos de Investigación, Permisos de Explotación y Concesiones de Explotación, de acuerdo a lo establecido en los Artículos 37 al 81 de la LMEs, se exige el canon de superficie de minas, figura establecida en el Artículo 41 de la Ley de Fomento a la Minería (LFM), cuyo hecho imponible es el uso privativo del dominio público minero. Uso que determina la ocupación de una porción de dominio público, de modo que se limita o excluye la utilización del mismo por otros interesados.

Como primera cuestión, Ilama la atención el empleo del término "canon" por el legislador español para referirse a esta figura, con la que en ocasiones en ese país se denomina también a otras relacionadas con o afectas a fines medioambientale ${ }^{25}$, o de compensación por el uso de bienes protegidos por el derecho de propiedad intelectual. Entonces: ¿se trata de algún gravamen que pueda enmarcarse en la clasificación tripartita del tributo recogida en el Artículo 2 de la Ley General Tributaria Española (LGT) ${ }^{26}$ ? Y de ser así, ¿se trata de un tributo de naturaleza medioambiental?

exclusivamente a esos Entes. Existe, por tanto, una situación que puede considerarse de monopolio ya que si un particu lar quiere acceder a la utilización o al aprovechamiento citados para realizar cualquier actividad debe acudir forzosamente a los mismos. La única alternativa que le cabe al particular para eludir el pago del precio público es la abstención de la realización de la actividad anudada a la utilización o aprovechamiento del demanio, pero ya hemos dicho que la abstención del consumo no equivale a libre voluntariedad en la solicitud. Esto significa que estamos en presencia de una prestación de carácter público en el sentido del art. 31.3 C.E., que, en cuanto tal, queda sometida a la reserva de ley. Por ello, si del análisis de los preceptos de la Ley de Tasas y Precios Públicos que se refieren a la creación y determinación de los elementos esenciales de los precios públicos se deduce que no respetan la reserva de ley, este párrafo a) del art. 24.1 deberá ser declarado inconstitucional”. Asimismo en sentencia Tribunal Supremo, № 1358/2009, de 12 de febrero de 2009, expresó que: "El que la utilización privativa o el aprovechamiento especial del dominio público local diese origen al abono de una tasa constituyó sin duda la innovación más significativa de la tesis de la citada Sentencia del Tribunal Constitucional № 185/1995, que sacó del campo de los precios públicos este supuesto, retornando así a la tradicional doctrina que arranca de la Ley de Tasas y Exacciones Parafiscales de 26 de diciembre de 1958, que conceptuó la utilización del dominio público como generadora del pago de una tasa, habiéndose mantenido así en toda la normativa posterior hasta la promulgación de la Ley №8, de 1989, en la cual esta actividad pasó a conceptuarse como generadora del abono de un precio público". De suerte pues que la labor jurisprudencial ha entendido que la naturaleza jurídica de esta exacción es tributaria y que se integra bajo la figura de una tasa.

${ }^{23}$ Aquellas en las que se transfiere el aprovechamiento de bienes del dominio público. En estos últimos casos, se considera que se produce un acrecentamiento patrimonial del concesionario, debido a que la Administración Pública traslada una de sus competencias la cual cede a un empresario privado a cambio de un canon, lo que ha dado lugar a la integración del hecho impon ible de diversos tributos (Sentencia Tribunal Supremo, de 31 de octubre de 1982, RJ 1982/1688), GALÁN (2009), pp. 345 y 351.

${ }^{24}$ Debe precisarse que aunque originalmente el Artículo 40 de la Ley 6/1997, estableció que "Quedan obligados al pago del canon de superficie de minas los titulares de derechos mineros de la sección C) del Artículo 3. de la Ley de Minas" la señalada modificación que la Ley $N^{\circ} 54 / 1980$ hizo de la Ley de Minas de 21 de julio de 1973 conforme a la que se consideraron aplicables a la sección D los preceptos de la Ley de Fomento de la Minería referidos a la sección C, supuso la modificación del hecho imponible del canon por lo que quedan comprendidas ambas secciones. Recordar que en la sección C, quedan comprendidos cuantos yacimientos minerales y recursos geológicos no estén incluidos en las secciones A y B y sean objeto de aprovechamiento conforme a la Ley de Minas; y en la sección $D$ se incluyen los carbones, los minerales radiactivos, los recursos geotérmicos, las rocas bituminosas y cualesquiera otros yacimientos minerales o recursos geológicos de interés energético que el Gobierno acuerde incluir en esta sección, a propuesta del Ministro de Industria y Energía, previo informe del Instituto Geológico y Minero de España.

${ }_{25}$ Por ejemplo, el "canon eólico" de Galicia fue creado mediante Ley del Parlamento de Galicia N 8/2009, por la que se regula el Aprovechamiento Eólico en Galicia y se crean el canon eólico y el Fondo de Compensación Ambiental este ha sido definido como un impuesto medioambiental propio de la Comunidad Autónoma que grava la contaminación paisajística provocada por la instalación de aerogeneradores utilizados en la producción de energía eólica. Su hecho imponible es la generación de afecciones e impactos visuales y ambientales adversos sobre el medio natural y sobre el territorio, como consecuencia de la instalación en parques eólicos de aerogeneradores afectos a la producción de energía eléctrica y situados en el territorio de la Comunidad Autónoma de Galicia (Artículo 11). Al respecto véase a RODRíGUEZ (2015).

${ }^{26}$ Ley $\mathrm{N}^{\circ} 58 / 2003$. Artículo 2 Concepto, fines y clases de los tributos.

1. Los tributos son los ingresos públicos que consisten en prestaciones pecuniarias exigidas por una Administración pública como consecuencia de la realización del supuesto de hecho al que la ley vincula el deber de contribuir, con el fin primordial de obtener los ingresos necesarios para el sostenimiento de los gastos públicos. 
Teniendo en cuenta que el numeral 2. Letra a) de la LGT, considera a las tasas como tributos cuyo hecho imponible consiste en la utilización privativa o el aprovechamiento especial del dominio público, la prestación de servicios o la realización de actividades en régimen de derecho público que se refieran, afecten o beneficien de modo particular al obligado tributario, cuando los servicios o actividades no sean de solicitud o recepción voluntaria para los obligados tributarios o no se presten o realicen por el sector privado; puede decirse que este "canon" que se aplica específicamente al sector minero, es técnica y realmente una tasa, es decir, un tributo ${ }^{27}$, y su fin a pesar de estar relacionado con las minas, no tiene carácter medioambiental. Ello porque es el uso privativo del dominio público minero, esto es, el otorgamiento de los derechos mineros a través de los respectivos permisos de exploración, permisos de investigación y concesiones de explotación de los recursos minerales incluidos en las secciones $C$ y $D$ del Artículo 3 de la LMEs.

En ese sentido, son sujetos pasivos de esta tasa, las personas físicas o jurídicas, así como sus herederos, causahabientes o cesionarios a quienes sean otorgados conforme a la legislación minera, los permisos y las concesiones de explotación de los recursos mineros de las secciones mencionadas. De esta forma, los titulares de derechos mineros de las secciones A y $B$ de la LMEs no son sujetos pasivos de esta obligación porque no son titulares de una concesión, sino de una simple autorización administrativa. Por otra parte, las normas que regulan el canon de superficie de minas en relación a la investigación y explotación de hidrocarburos son objeto de regulación especial lo que excede al propósito de esta investigación ${ }^{28}$.

A tenor de lo dispuesto en el Artículo 41 LFM, y en el Artículo 11 del Decreto que lo desarrolla, se realiza una distinción de acuerdo con la cual, en los permisos de investigación y concesiones de explotación otorgadas con anterioridad a la LMEs, la base imponible era la hectárea, y para los otorgados conforme a ella, la base imponible es la cuadrícula minera ${ }^{29}$, y se determinará en función de la extensión superficial del permiso o concesión y la clase de permiso o concesión de que se trate.

Del mismo modo, se exigirá conforme a las bases y tipos, que son fijos, contenidos en las tarifas establecidas en Artículo 11 del Real Decreto № 1167/1978, determinándose la cuota para cada año multiplicando la tarifa inicial por el coeficiente de actualización respectivo. Así en la tarifa primera, para permisos de exploración por cada cuadrícula y año, se pagarán 1,2 euros. En cuanto a la tarifa segunda, aplicable a los permisos de investigación otorgados con arreglo a legislaciones anteriores a la LMEs, por cada 30 hectáreas o fracción y año se pagarán 22,5 euros. $Y$ en el caso de los otorgados con arreglo a la LMEs, por cada cuadrícula y año se pagarán: 22,5 euros. En la tarifa tercera, relativa a las concesiones de explotación que sean otorgadas con arreglo a legislaciones anteriores a la LMEs, por cada 10 hectáreas o fracción y año se pagarán 15 euros. Y con respecto a las otorgadas con arreglo a la LMEs, por cada cuadrícula y año se pagarán 45 euros.

A tenor de lo dispuesto en el Artículo 42 de la LFM, el devengo para los permisos de exploración e investigación y las concesiones de explotación, tendrá lugar con carácter general,

Los tributos, además de ser medios para obtener los recursos necesarios para el sostenimiento de los gastos públicos, podrán servir como instrumentos de la política económica general y atender a la realización de los principios y fines contenidos en la Cons titución. 2. Los tributos, cualquiera que sea su denominación, se clasifican en tasas, contribuciones especiales e impuestos:

a) Tasas son los tributos cuyo hecho imponible consiste en la utilización privativa o el aprovechamiento especial del dominio público, la prestación de servicios o la realización de actividades en régimen de derecho público que se refieran, afecten o beneficien de modo particular al obligado tributario, cuando los servicios o actividades no sean de solicitud o recepción voluntaria para los obligados tributarios o no se presten o realicen por el sector privado".

27 Según explica MARTíNEZ (2011), p. 23, en el ordenamiento tributario vigente en España se utiliza la expresión "canon" para referirla al tributo que se percibe por la utilización del dominio público, reservando el término tasa al que aparece relacionado con la prestación de servicios públicos.

28 Dicha regulación especial deviene de la aplicación de la Ley N²12/2007. Al respecto puede consultarse a MARTíNEZ (2011), pp. 119-131.

${ }^{29}$ De acuerdo con lo establecido en el Artículo 75 de la Ley de Minas, una cuadrícula minera es el volumen de profundidad indefinida cuya base superficial quede comprendida entre dos paralelos y dos meridianos, cuya separación sea de veinte segundos sexagesimales, que deberán coincidir con grados y minutos enteros y, en su caso, con un número de segundos que necesariamente habrá de ser veinte o cuarenta. 
el día en que nazca el derecho a que se refiere el acuerdo de otorgamiento, esto es, la fecha en la que el concesionario firme el acuse de recibo del título de otorgamiento, abonándose como canon la parte de las cuotas anuales que proporcionalmente correspondan desde la fecha del otorgamiento hasta el final del año natural.

Asimismo, para los permisos de investigación y concesiones de explotación, y para las anualidades posteriores a la del año en que fueron otorgados, el devengo tendrá lugar el día primero de enero de cada año natural. En tanto que, las tarifas establecidas para los permisos de exploración corresponden al año completo de duración por el que se otorgan. Esto es, tienen validez anual, y su abono deberá repetirse en caso de ser concedida la prórroga del permiso por otro año, todo ello a tenor de lo establecido en el artículo citado, en concordancia con lo dispuesto en el Artículo 12 RD № 1167/1978.

Cuando se produzca la renuncia o caducidad de los permisos de investigación, se dejará de devengar el canon el día en que sea aceptada la renuncia o se declare la caducidad (Artículo 42 LFM). En ese sentido, se declararán caducados los permisos cuando el titular deje de satisfacer el importe del canon de superficie correspondiente y, exigido como sea por la vía de apremio, no lo satisfaga en los plazos marcados en el vigente Reglamento General de Recaudación ${ }^{30}$.

\subsubsection{El problema del marco legislativo aplicable, su naturaleza jurídica y el sujeto activo de la obligación}

En la actualidad el primer problema del canon de superficie de minas español, estriba en identificar el marco legal aplicable, de él derivan otras situaciones confusas. Resulta complejo identificar el marco legal fundamentalmente, por los cambios que se han introducido en la legislación minera, que son posteriores a su regulación original de 1966. También porque el legislador no ha sido cuidadoso con la técnica jurídica empleada en las disposiciones derogatorias, lo que ha dado lugar a que para su regulación resulten aplicables diversas normas $^{31}$. De manera que sería necesaria - cuando menos conveniente- su reordenación.

Por una parte, deben tenerse en cuenta los Artículos 40 al 43 de la LFM y los Artículos 8 a 17 del Real Decreto № 1167/1978, de 2 de mayo, por el que se desarrolla el Título III, Capítulo II de la LFM, así como la Disposición Final Segunda de la Ley №54/1980, de 5 de noviembre, de modificación de la LMEs, que si bien establecía un mandato al Gobierno para que en el plazo de un año remitiese a la Cortes Generales un proyecto de Ley de modificación del canon de superficie establecido en la LFM, este no fue cumplido.

Por otra parte, no puede perderse de vista que la Ley №62/2003, de 30 de diciembre, de Medidas Fiscales, Administrativas y del Orden Social, en su Artículo 23 incorporó una nueva disposición final 3a en el Texto Refundido de Tasas Fiscales, de acuerdo con la cual: "La Ley de Presupuestos Generales del Estado podrá modificar, de conformidad con lo previsto en el apartado 7 del art. 134 de la CE, las bases y tipos contenidos en las tarifas del art. 10 del presente $T . R^{\prime \prime}$. De esta forma, las leyes de presupuestos generales del Estado tienen la potestad de modificar las tarifas del Artículo 10 del Texto Refundido de Tasas Fiscales. Sin embargo, el legislador no tuvo en cuenta que la LFM no modificó en este extremo el mencionado Texto Refundido, con lo cual las tarifas del canon actualmente vigentes, prescindiendo del problema de la actualización de sus cuantías, se encuentran recogidas en el Artículo 41 de la LFM y no en el Artículo 10 del Texto Refundido de Tasas Fiscales, precepto que debe entenderse derogado por la indicada $\mathrm{LFM}^{32}$.

\footnotetext{
${ }^{30}$ Artículo 14.2. del Decreto N³059/1966: "la falta de pago del canon lleva aparejada la caducidad de la concesión respectiva por ministerio de la Ley". Véase también Real Decreto N939/2005. De acuerdo con lo dispuesto en el Artículo 15 del Real Decreto N¹167/1978, los delegados provinciales del Ministerio de Industria procederán a decretar en todo caso la caducidad dentro del plazo máximo de quince días a partir del recibo de la propuesta formulada por los Organismos provinciales del Ministerio de Hacienda.

${ }^{31}$ MUNOZ (2006), p. 4.

${ }^{32}$ MUÑOZ (2006), p. 16.
} 
A la dificultad de identificar el marco jurídico aplicable se suma la de precisar su naturaleza jurídica. Aunque conforme a lo visto hasta ahora resulta evidente que se trata de una tasa, se ha discutido si su exigencia deriva de la prestación de un servicio público o de la utilización privativa o aprovechamiento especial del dominio público. ¿Qué es lo relevante en el pago del canon, la autorización en sí, o los derechos mineros que atribuye respecto de un bien de titularidad estatal?

El origen de una vertiente de esta discusión se remonta, a la consideración del canon como un precio público que hacía la Ley №8/1989, de 13 de abril, de tasas y precios públicos, lo que supuso un paréntesis en la naturaleza de tasa fiscal que esa figura había tenido históricamente en el ámbito de la minería en el derecho español ${ }^{33}$. Pero precisar si se trataba de un precio público o de una tasa fiscal, tendría sus consecuencias importantes en la práctica. Ya que se trata de figuras sometidas a regímenes jurídicos distintos.

En este orden de ideas, uno de los aspectos más importantes del debate es que si el canon en lugar de un tributo, fuera un precio público, no le serían aplicables los principios constitucionales tributarios, como los de reserva de ley y capacidad económica, y, no serían aplicables tampoco las actualizaciones que establecieron las sucesivas Leyes de Presupuestos Generales del Estado, para los tipos de cuantía fija de las tasas de la Hacienda estatal ${ }^{34}$.

En todo caso, el panorama cambió con la llegada de la Ley №25/1998, de 13 de julio, de modificación del régimen legal de las tasas estatales y locales y de reordenación de las prestaciones patrimoniales de carácter público, que tuvo su fundamento en la Sentencia del Tribunal Constitucional № 185/1995, de 14 de diciembre, que declaró la inconstitucionalidad de varios preceptos de la Ley № 8/1989 y afectó también al canon minero. Este último pasó a ser considerado nuevamente y sin lugar a dudas, una tasa fiscal en lugar de un precio público ${ }^{35}$.

Ahora bien, al respecto conviene precisar la diferencia entre ambas categorías. Así según explica García, el precio público vendría a ser una especie del género "precio", que jurídicamente es una prestación basada en el principio de equivalencia y justicia conmutativa, satisfecha por la entrega de un bien o por la prestación de un servicio. Un precio, para ser público debe reunir tres condiciones: resultar percibido por un ente público en el marco de una normativa de Derecho Público; ser exigido por la prestación de una actividad que, en un sentido genérico, podría calificarse como servicio público y, por fin, el hecho de que como consecuencia de este régimen público, la cuantía del precio público se alejaría del principio de equivalencia, sin llegar a cubrir normalmente el coste del servicio prestado. Asimismo, en el precio público no se regula un hecho imponible, y aunque se mantiene en la esfera del Derecho Público, no es un tributo ${ }^{36}$.

A mayor abundamiento explican Martín et al. ${ }^{37}$ que en el derecho español se califican como precios públicos las contraprestaciones recibidas por un ente público, como consecuencia de la prestación de servicios o la realización de actividades administrativas cuando es voluntaria su solicitud o recepción y ese servicio es prestado o la actividad es realizada también por el sector privado; en ese sentido, el particular podría optar libremente entre acudir al ente público

\footnotetext{
${ }^{33}$ A este respecto puede consultarse el estudio sobre la evolución histórica del canon de superficie de minas español, que hace en su Tesis Doctoral FERNÁNDEZ (2015), pp. 39-72. También POZUELO (1986). El canon de superficie de Minas se estructura como un tributo independiente en la Ley de Tributación Minera de 29 de diciembre de 1910. Posteriormente la Ley de Reforma Tributaria de 16 de diciembre de 1940 lo incorpora en la Contribución Industrial. En la Reforma de 1957 de Navarro Rubio, la Ley de 26 de diciembre de ese año, crea, dentro del Impuesto Industrial, la Cuota de Licencia y la Cuota de beneficios, incluyéndose el canon en la de Licencia. Finalmente, en el Texto refundido de 1966 se configura como tasa fiscal y así continua hasta la actualidad.

${ }^{34}$ En razón que producto de la Ley $N^{\circ} 8 / 1989$, el canon había perdido su naturaleza de tasa, se invocaba que no podían ser aplicables las actualizaciones que establecían las Leyes de Presupuestos para dicho tributo, y que implicaban la elevación del monto del mismo. De ahí que creció la conflictividad en torno al canon de superficie minera. En ese sentido, se alegaba que las referidas actualizaciones no podían afectarlo por carecer de la preceptiva habilitación legal exigida por el artículo 134-7 de la Constitución, que impide a la Ley de Presupuestos la creación de tributos, si bien permite que los modifique siempre y cuando una ley tributaria sustantiva así lo prevea. La posición de los Tribunales Superiores de Justicia sobre el tema no fue uniforme. Así, en numerosas decisiones se concluyó que no eran aplicables las actualizaciones (Castilla-La Mancha); en otras se resolvió precisamente lo contrario (Extremadura, Aragón y Asturias); y en algunos casos no existía un criterio uniforme (Andalucía). MUÑOZ (2006), p. 20.

${ }^{35}$ Respecto a la importancia de esta decisión se recomienda el artículo de GARCÍA (1997), p. 53.

${ }^{36}$ GARCÍA (2012), pp. 277-279.

${ }^{37}$ MARTín et al. (2010), p. 82.
} 
o al privado para recibir el servicio o actividad, producto de lo cual pagará un precio público o privado respectivamente. Resulta pues una nota distintiva importante, la coactividad en la recepción o solicitud del servicio o la actividad administrativa que es inexcusable en el caso de las tasas. Asimismo, aunque ambas figuras son ingresos de derecho público, los tributos y en particular, las tasas, son obligaciones que no tienen causa en un contrato.

Así, se concuerda con la opinión expresada por Muñoz para quien no hay duda de que el canon de superficie de minas es una tasa fiscal, que grava la utilización privativa o el aprovechamiento especial del dominio público y no la prestación de un servicio público. Principalmente, porque el Estado no presta ningún servicio público en este ámbito ${ }^{38}$.

En ese sentido, es menester precisar también que en el ordenamiento jurídico español, las funciones y servicios en materia de minas fueron trasferidas a las Comunidades Autónomas, a quienes se les encomienda el otorgamiento de los permisos de exploración, de investigación y de concesiones de explotación de los recursos de las secciones C y D de la LMEs, solicitados en terrenos situados dentro de su territorio; pero la titularidad del demanio minero la sigue ostentando el Estado. Así, como puede observarse, lo que se ha transferido a las Comunidades Autónomas es únicamente su gestión y control. De manera que es entonces el uso de ese dominio público lo que legitima la exigencia del canon.

Esta diferencia entre titularidad y gestión, da lugar al pago de dos tipos de tasas totalmente distintas y compatibles entre sí. Las de la Comunidad Autónoma que sí gravan la prestación de servicios públicos en relación con la actividad minera; y el canon de superficie minera que se exige por el uso del dominio público minero, cuya titularidad sigue ostentando el Estado. Considerar lo contrario, daría lugar a un solapamiento de tributos que originarían doble imposición entre el canon y las tasas que gravan estos servicios que, como se ha dicho, se han convertido en tributos propios de las Comunidades Autónomas al haber asumido estas las competencias sobre la materia ${ }^{39}$.

Finalmente, conforme a todo lo dicho hasta ahora, la consideración del canon de superficie de minas como una tasa fiscal implica que en principio, al tratarse de un tributo debería estar presente en alguna medida el principio de capacidad económica. Entonces: si el hecho imponible es el uso privativo o aprovechamiento del dominio público minero, ¿de qué forma se tiene en cuenta el principio de capacidad económica?

Al respecto, se concuerda con lo expresado por Martín et al., en que de forma general, tal y como viene definida la tasa en la LGT, no se refleja en modo alguno la capacidad económica de los sujetos pasivos, porque no constituye una manifestación de fuerza económica, por ello, de forma contraria a lo que ocurre con los impuestos, en el caso de las tasas, se puede admitir que aun estando presente el principio de capacidad económica, no sea este el único criterio de graduación de la prestación, y se podrán tener en cuenta criterios genéricos de capacidad económica de los sujetos obligados al pago ${ }^{40}$.

Si bien, desde otro punto de vista no parece del todo despreciable la idea de que exista alguna manifestación de capacidad económica en el canon bajo análisis. Ello porque a pesar de tratarse de una exacción que se exige por el otorgamiento de permisos y concesiones sobre bienes de dominio público que tienen como consecuencia la adquisición del uso privativo de los mismos o su aprovechamiento, lo cierto es que con ella se produce una transferencia patrimonial (sobre todo en el caso de las concesiones, probablemente también un

\footnotetext{
${ }^{38}$ MUÑOZ (2006), p. 20.

${ }^{39}$ MUÑOZ (2006), p. 21. El autor se vale además de un ejemplo para apoyar sus dichos. Así explica que en el caso de la Comunidad de Castilla y León, la Ley N¹2/2001, regula en sus artículos 147 al 150 la Tasa en materia de minas. En ese sentido, de acuerdo a lo dispuesto en el artículo 147 ejusdem constituye el hecho imponible de esta tasa la prestación de los servicios administrativos relativos a la ordenación, las concesiones, las autorizaciones preceptivas y la inspección de la actividad minera. en tanto que son sujetos pasivos de la misma quienes soliciten o en cuyo interés se realicen las actuaciones constitutivas del hecho imponible (Artículo 148).

${ }^{40}$ MARTín et al. (2010), p. 81.
} 
acrecentamiento patrimonial en sede del concesionario), susceptible de integrar el hecho imponible de diversos tributos por ejemplo, por su constitución, mantenimiento y transmisión ${ }^{41}$.

\subsection{El derecho de vigencia y las regalías mineras en el derecho peruano}

En términos muy similares a lo que ocurre en Chile, Perú es un país de amplia tradición minera. De hecho, el cobre es también el mineral cuya extracción genera la mayor cantidad de divisas, alcanzando aproximadamente un $23 \%$ del valor total de las exportaciones en los últimos 10 años $^{42}$. Sin embargo, como se verá de inmediato, el sistema de ordenación minera y producto de ello, el régimen especial de tributos y otros derechos exigibles a la actividad, distan mucho de la tradición chilena.

La $\mathrm{CPe}^{43}$, establece en su Artículo 66 que los recursos naturales renovables y no renovables son patrimonio de la Nación, y que el Estado es soberano en su aprovechamiento. Asimismo, que una Ley Orgánica fijará las condiciones para su utilización y otorgamiento a particulares. Esa Ley, es la $\mathrm{LGM}^{44}$, la cual fija las condiciones para el otorgamiento de los derechos de exploración y explotación de los recursos minerales.

La declaratoria que hace el Artículo 66 constitucional ha llevado a la doctrina a considerar a las minas y los recursos minerales como patrimonio propio del Estado ${ }^{45}$. Con ello a su vez se distingue entre ingresos originarios o patrimoniales, esto es, los que se obtienen de los intercambios que el Estado realiza como sujeto de una relación económica, es decir, que los obtiene de fuentes propias de riqueza, cuando explota, arrienda o vende sus propiedades, cuando obtiene ganancias por medio de sus empresas y por el ejercicio de actividades industriales, comerciales, mineras, petroleras, agrícolas, entre otras; e ingresos derivados esto es, aquellos que obtiene el Estado en su condición de tal y que constituyen apropiaciones legítimas del patrimonio de los particulares sustentadas en el poder de imperio, pero que no responden a un concepto retributivo-compensatorio ${ }^{46}$.

Desde la perspectiva de los ingresos derivados, la minería en Perú, además de estar sometida al Impuesto a la Renta, también es gravada con el Impuesto Especial a la Minería (IEM) y el Gravamen Especial a la Minería (GEM), así como por otras exacciones de indiscutible naturaleza tributaria. Pero existen también otras figuras de las que se ha negado una eventual naturaleza tributaria, al ser consideradas "derechos" o "compensaciones" relacionadas fundamentalmente con el carácter demanial de las minas ${ }^{47}$.

La actividad minera entonces se regula desde la perspectiva de su organización y aprovechamiento, con carácter general en la LGM, que reafirma que todos los recursos minerales pertenecen al Estado, cuya propiedad es inalienable e imprescriptible ${ }^{48}$. El ejercicio de las actividades mineras, excepto el cateo, la prospección y la comercialización, se realizan exclusivamente bajo el sistema de concesiones, al que se accede bajo procedimientos que son de orden público. Las concesiones se otorgan tanto para la acción empresarial del Estado, cuanto de los particulares, sin distinción ni privilegio alguno. De esta forma, las actividades de exploración, explotación, beneficio, labor general y transporte minero, pueden ser ejecutadas por personas naturales y jurídicas nacionales o extranjeras, a través del sistema de concesiones (Artículo 7 ejusdem).

\footnotetext{
${ }^{41}$ GALÁN (2009), p. 351.

${ }^{42}$ LANDA (2017), p. 141.

${ }^{43}$ Constitución Política del Perú, de 1993.

${ }^{44}$ Decreto Supremo № 014-92-EM, de 1992.

${ }^{45}$ Sobre el tema pueden consultarse entre otros, los trabajos de DE LA TORRE (2005); ORÉ (2008); ZUZUNAGA (2011); ZEGARRA (2015) y LANDA (2017).

${ }^{46}$ ZUZUNAGA (2011), p. 2.

47 Para profundizar al respecto se recomiendas los trabajos de ZEGARRA (2015) y ZUZUNAGA (2011).

${ }^{48}$ Así lo establece la ley en comento en su Título Preliminar, en el que también se exceptúan del ámbito de aplicación, el petróleo e hidrocarburos análogos, los depósitos de guano, los recursos geotérmicos y las aguas minero-medicinales.
} 
El otorgamiento de la concesión minera da lugar a que los particulares puedan aprovechar de forma privada, bienes que son de dominio público ${ }^{49}$ y por tanto, deban abonarse al Estado una serie de cantidades que han sido catalogadas como "recursos públicos originarios". Por una parte está el llamado Derecho de Vigencia, establecido en el Artículo 39 de la LGM; de igual forma la Regalía Minera Legal, creada por la Ley 28.258 de Regalía Minera, reformada por la Ley $N^{\circ} 29.788$ y existen también las llamadas regalías contractuales.

En ese sentido, el Derecho de Vigencia se entiende como una retribución económica que debe pagar el concesionario por el mantenimiento de la concesión minera ${ }^{50}$. En palabras del Tribunal Constitucional Peruano ${ }^{51}$, es un ingreso originario para mantener la autorización del Estado para explorar y explotar la concesión. De este derecho de vigencia se desprende por una parte, una obligación pagadera por la formulación del petitorio de la concesión minera, y por otro lado, una obligación de pago anual que se configura cada primero de enero, a partir del año siguiente a la formulación del petitorio de la concesión, y cuya falta de pago por dos años es causal de caducidad de las concesiones mineras (Artículos 39 y 59 de la LGM). El monto del Derecho de Vigencia es el equivalente en moneda nacional peruana a US\$ 3.00 por año y por hectárea otorgada o solicitada. Para los pequeños productores mineros y para productores artesanales ${ }^{52}$, el Derecho de Vigencia será el equivalente en moneda nacional peruana a US\$ 1.00 y 0.50 , por año y por hectárea otorgada o solicitada respectivamente.

Por su parte, la regalía minera, figura creada en el año 2004 por la Ley $N^{\circ} 28.258$, ha sido definida como la contraprestación económica que los sujetos de la actividad minera pagan al Estado por la explotación de los recursos minerales metálicos y no metálicos. El término "sujetos de la actividad minera" incluye a las empresas integradas, a los titulares de las concesiones mineras y a los cesionarios que realizan actividades de explotación de recursos minerales metálicos o no metálicos, según lo establecido en el Título Décimo Tercero de la LGM y sus normas modificatorias.

Ahora bien, existe también la posibilidad de que el Estado al asignar el recurso mineral haya acordado con el particular el pago de una "regalía contractual". En este supuesto, la "regalía minera contractual" aparece como una modalidad mediante la cual el Estado "transfiere" la concesión minera a cambio de una contraprestación, conforme surge del marco previsto para el respectivo proceso de promoción de inversión privada en las empresas que conforman la actividad del Estado, regulado mediante Decreto Legislativo №67453.

\footnotetext{
${ }^{49}$ Lo que como se explicó en Perú se entiende como propiedad, respecto de lo cual esta autora se aparta por considerar que la forma más adecuada de explicar el vínculo del Estado con las minas en entenderlo en un ámbito de potestades, lo que se acerca más a las teorías funcionalistas.

${ }^{50}$ RODRÍGUEZ y TORRES (2010), p. 46.

51 Sentencia N0048-2004-PI-TC del Tribunal Constitucional, de fecha 1 de abril de 2005, que resuelve la demanda de inconstitucionalidad interpuesta contra los artículos 1, 2, 3, 4 y 5 de la Ley N²8258 - Ley de Regalía Minera y sus modificatorias.

52 De acuerdo con el artículo 91 de la LGM: Son pequeños productores mineros los que: En forma personal o como conjunto de personas naturales, o personas jurídicas conformadas por personas naturales o cooperativas mineras o centrales de cooperativas mineras se dedican habitualmente a la explotación y/o beneficio directo de minerales; quienes posean, por cualquier título, hasta dos mil $(2,000)$ hectáreas, entre denuncios, petitorios y concesiones mineras; y, además; quienes posean, por cualquier título, una capacidad instalada de producción y/o beneficio no mayor de trescientas cincuenta (350) toneladas métricas por día. En el caso de los productores de minerales no metálicos y materiales de construcción, el límite máximo de la capacidad instalada de producción y/ o beneficio será de hasta un mil doscientas $(1,200)$ toneladas métricas por día. En el caso de los yacimientos metálicos tipo placer, el límite máximo de la capacidad instalada de producción y/o beneficio, será de tres mil $(3,000)$ metros cúbicos por día.

Por su parte, son productores mineros artesanales los que: En forma personal o como conjunto de personas naturales o personas jurídicas conformadas por personas naturales, o cooperativas mineras o centrales de cooperativas mineras se dedican habitualmente y como medio de sustento, a la explotación y/o beneficio directo de minerales, realizando sus actividades con métodos manuales y/o equipos básicos; y los que posean, por cualquier título, hasta un mil $(1,000)$ hectáreas, entre denuncios, petitorios y concesiones mineras; o hayan suscrito acuerdos o contratos con los titulares mineros según lo establezca el reglamento de la presente ley; y, además; quienes posean, por cualquier título, una capacidad instalada de producción y/o beneficio no mayor de veinticinco (25) toneladas métricas por día. En el caso de los productores de minerales no metálicos y de materiales de construcción, el límite máximo de la capacidad instalada de producción y/o beneficio será de hasta cien (100) toneladas métricas por día. En el caso de los yacimientos metálicos tipo placer, el límite máximo de capacidad instalada de producción y/o beneficio será de doscientos (200) metros cúbicos por día.

${ }^{53}$ Decreto Legislativo №674, de 1991; ZUZUNAGA (2011), p. 8. Este contrato de "transferencia" es uno atípico y especialmente diseñado por el Estado y el particular, para el recurso involucrado. En términos generales, una contraprestación pactada en un proceso de privatización puede establecerse de acuerdo con cualquier modalidad permitida por el derecho común, la que incluye la
} 
Por su parte, el pago de la regalía minera que se creó en el año 2004 en el marco de la Ley № 28.258 se determinaba sobre el valor del concentrado o su equivalente. Pero, con la entrada en vigencia de la Ley № 29.788 en el 2011, la Nueva Regalía Minera se establece sobre la utilidad operativa trimestral con una tasa efectiva entre el 1 y el $12 \%$ de acuerdo a los márgenes operativos ${ }^{54}$. Asimismo, el monto efectivamente pagado por concepto de regalía minera será considerado como gasto para efectos del Impuesto a la Renta en el ejercicio correspondiente.

En todo caso, en el contexto de la actividad minera en Perú, se sostiene que tanto la llamada "regalía minera legal" como la "regalía minera contractual" tienen como propósito dar valor a la contraprestación o compensación del detrimento del patrimonio del Estado, basándose en la producción obtenida como consecuencia de la explotación de la concesión minera y abonándose periódicamente durante la vida útil de la mina.

Finalmente, una breve mención aparte merece el canon minero, el cual en Perú, de forma muy distinta a lo que ocurre en el derecho español, ha sido definido por el Artículo 9 de la La Ley de Canon, ley $\mathrm{N}^{\circ} 27.506^{55}$, como la participación efectiva y adecuada de la que gozan los gobiernos regionales y locales del total de los ingresos y rentas obtenidos por el Estado por la explotación económica de los recursos naturales.

Así en el derecho peruano, el canon minero no equivale como en el derecho español a una tasa fiscal que deba satisfacer el concesionario, sino que está constituido por el $50 \%$ del total de ingresos y rentas obtenidas por el Estado en la actividad minera, por el aprovechamiento de los recursos minerales, metálicos y no metálicos, que será distribuido entre los gobiernos regionales y locales (Artículo 9 de la Ley № 27.506) ${ }^{56}$. Por ello en opinión de algún autor, en el derecho peruano con la llegada de la Ley del Canon Minero se rompió el nexo histórico (heredado del derecho español) entre concesionario y el reconocimiento que este debe de tener del poder demanial del Estado, situación que vino a corregirse en el 2004 con las regalías mineras ${ }^{57}$.

\subsubsection{El problema de la naturaleza jurídica de estos "derechos" o "contraprestaciones"}

Aunque parece claro que debido al carácter patrimonialista del dominio minero en el Perú, el Estado se encuentra habilitado para percibir ciertas cantidades de dinero en calidad de compensaciones, producto de la entrega o aprovechamiento que por medio de las concesiones hagan los particulares, se ha discutido cuál es realmente la naturaleza jurídica tanto del Derecho de Vigencia como de la Regalía Minera Legal. Si se observa, ambas son exacciones impuestas por el Estado en virtud de la ley, de manera que no devienen del acuerdo de voluntades. Asimismo, sobre todo en el caso de la regalía, existen elementos para atribuirles una eventual naturaleza tributaria.

\footnotetext{
fijación de montos determinados, determinables o no determinables. Así, en casos en los que, por ejemplo, el valor del yacimiento no pueda ser establecido, por cuanto se trata de una privatización con el propósito de que el particular explore y explote las concesiones involucradas, la contraprestación que se pacta suele ser, justamente la "regalía". En ese sentido, la tercera dis posición final de la Ley №28.258 incorporada mediante Ley №28.323 dispuso que a la "regalía contractual minera" se le aplican únicamente los términos establecidos en el contrato de transferencia de concesiones respectivo, celebrado entre el particular y el Estado, no siéndole de aplicación -por compartir igual naturaleza jurídica- la regalía minera legal. Exactamente, la mencionada disposición final establece que: "Los proyectos mineros que hubieren pactado regalía minera antes de la vigencia de la presente ley, se rigen por sus respectivos contratos".

${ }^{54} \mathrm{El}$ monto a pagar por concepto de la regalía minera será el mayor monto que resulte de comparar el resultado de aplicar sobre la utilidad operativa trimestral la tasa efectiva señalada en el Anexo de la Ley 29788, (la tasa es establecida en función al margen operativo del trimestre) y el uno por ciento (1\%) de los ingresos generados por las ventas realizadas en el trimestre calendario.

${ }^{55}$ Ley $\mathrm{N}^{\circ} 27.50$, de 2001. El establecimiento de este canon encuentra su fundamento en el artículo 77 de la Constitución Peruana según el cual corresponden a las respectivas circunscripciones, conforme a ley, recibir una participación adecuada del total de los ingresos y rentas obtenidos por el Estado en la explotación de los recursos naturales en cada zona en calidad de canon.

${ }^{56}$ Sobre algunos problemas del canon minero en Perú, puede leerse a MANCO (2002).

57 ORÉ (2008). En Perú coexisten 6 tipos de cánones, a saber: minero, petrolero, pesquero, forestal, gasífero y de hidrocarburos. El canon minero, corresponde a la compensación que será distribuida de los ingresos recaudados a las zonas donde se explotan los recursos minerales, garantizándose la participación directa de la población local en el beneficio del reparto. Medida que se considera justificada en que dicha población será la que recibirá el mayor impacto cuando estos recursos se agoten.
} 
Curiosamente, aunque se le define como "contraprestación" y no como alguna de las categorías del concepto tributo, los sujetos de la actividad minera tienen la obligación de presentar la declaración y efectuar el pago de la regalía minera correspondiente a cada trimestre, en la forma y condiciones que establezca la Superintendencia Nacional de Administración Tributaria (SUNAT), declaración que deberá contener la determinación de la base de cálculo de la regalía minera. Entonces: ¿Son tributos?

Al margen de las consideraciones doctrinarias a favor o en contra, el Tribunal Constitucional Peruano ${ }^{58}$, mediante sentencia en la que se resuelve la solicitud de inconstitucionalidad interpuesta contra los Artículos 1, 2, 3, 4 y 5 de la Ley № 28.258 de Regalía Minera, ya se pronunció sobre la naturaleza jurídica de estas figuras y ha puesto de relieve algunos de sus aspectos esenciales.

Por una parte, ha establecido que el Derecho de Vigencia es un ingreso originario, un tipo de retribución económica, que tiene como propósito precisamente mantener vigente la concesión a favor del titular, esto es, conservar la autorización del Estado para explorar y explotar la concesión. Asimismo, que se diferencia de la Regalía Minera Legal en que esta última es la contraprestación que abona el titular de la concesión en compensación por el detrimento de la pérdida patrimonial del Estado, que dispuso del recurso in situ a favor del aludido titular.

En la misma sentencia, explica el Tribunal que la Regalía Minera es una "retribución económica contraprestativa o compensatoria" por el usufructo de lo que se extrae. En tanto que el Derecho de Vigencia es una retribución económica por el mantenimiento de la concesión, y cuyo incumplimiento priva de efecto a la concesión misma, constituyéndose en causal de caducidad de la concesión. Diferencias que pueden constatarse en la forma de cálculo de cada una; así, el Derecho de Vigencia, de periodicidad anual, tomará en cuenta el número de hectáreas otorgadas o solicitadas en concesión, y no la producción obtenida, como en el caso de la Regalía.

En ese sentido, entiende el Tribunal que la regalía minera se exige por el uso o aprovechamiento de un bien que, "siendo propiedad de la nación", es concedido al titular de la actividad minera para que pueda obtener el dominio sobre los productos del mismo. La Regalía Minera es pues una obligación legal definida como contraprestación por la explotación del recurso, que ha sido otorgado a favor del particular mediante el título de "concesión", acto administrativo por el que se le reconoció a dicho particular la posibilidad de un aprovechamiento privado de bienes de dominio público, generando entre el Estado y el citado particular una relación jurídica subordinada al interés público y no de carácter sinalagmático.

Así al crearse la Regalía Legal como obligación pecuniaria a favor del Estado, se comprende en su aplicación a toda concesión minera, otorgada antes o después de creada (Salvo en los casos de concesiones mineras que comprendidas en proyectos materia de convenios de estabilidad celebrados al amparo de la Ley General Minera), en razón al estado de sujeción en que se encuentra el particular respecto del Estado, entidad suprema que siempre mantiene una potestad (el dominio) respecto de las concesiones mineras.

Pese a que en las consideraciones del Tribunal Constitucional se estima que el dominio del Estado tiene una naturaleza patrimonialista, el vínculo generado entre el Estado y el concesionario minero deviene en una relación jurídica subordinada al interés público y no de carácter sinalagmático.

Todas esas consideraciones en opinión de quien escribe, hacen caer en contradicción a un Tribunal que en su intento por negar el carácter tributario de ambas figuras no hace sino confirmar no solo que el gravamen en cuestión (la regalía) deriva del carácter demanial de las minas; sino además que su naturaleza jurídica debería ser entendida en un ámbito de potestades y no de propiedad, lo que trae como consecuencia que aunque no se hace, debería reconocerse su naturaleza tributaria.

${ }^{58}$ Mediante sentencia del Tribunal Constitucional, N0048-2004-PI-TC, de 1 de abril de 2005. 


\subsection{Las llamadas "patentes mineras" en el derecho chileno}

El artículo de la Constitución Política chilena (art. 19 № 24으, inc. 7ㅇ) se refiere al régimen de amparo como el sistema por medio del cual se obtendrá el cumplimiento de la obligación de desarrollar la actividad necesaria para satisfacer el interés público que justifica el otorgamiento de la concesión minera ${ }^{59}$. Así, el régimen de amparo de las concesiones mineras en Chile, impone el pago de lo que se ha denominado la "patente anual", prevista en los artículos 142 al 145 del $\mathrm{CMCh}^{60}$, la cual puede ser de exploración o de explotación según la concesión de que se trate. En ese sentido, una pertenencia se considerará "amparada" siempre que su titular (el concesionario) cumpla con las exigencias previstas en la ley y, por argumento en contrario, estará desamparada cuando no lo haga.

Téngase en cuenta que en el derecho de minería existen dos formas de amparo: el amparo por trabajo (amparo directo) y el amparo por el pago de la patente anual (amparo indirecto). En tanto que la combinación de ambos, daría lugar a un sistema mixto. El amparo por trabajo obliga al concesionario a la efectiva explotación de los yacimientos que han sido concedidos, en tanto que el amparo por el pago de la patente anual, tal como su nombre lo indica (en términos similares a lo que ocurre con el derecho de vigencia en el ordenamiento jurídico peruano), conlleva simplemente a satisfacer el monto previsto en la forma establecida para el mantenimiento de la concesión. De tal suerte que la consecuencia del "desamparo" entonces, es la caducidad de la concesión ${ }^{61}$.

En Chile se ha optado por un amparo indirecto del derecho, que se concreta con la exigencia de las patentes mineras ${ }^{62}$. Razón por la cual la falta de pago pone al titular de la concesión en una situación de desamparo que puede derivar en la caducidad del título. De esta forma, el sistema chileno tiende en forma indirecta al cumplimiento de la obligación constitucional la que consiste en el pago de la patente anual que se satisface en proporción a la cantidad de hectáreas que tenga su titular ${ }^{63}$.

Pero una cosa es el régimen de amparo propiamente tal como sistema de cumplimiento y otra es la patente como cantidad de dinero. Es decir que el sometimiento de las concesiones al régimen de amparo no es contrario al carácter de tributo de la patente, pues aunque ambas nociones se encuentran interconectadas ya que el régimen de amparo se satisface a través del pago de la patente son dos conceptos distintos. Piénsese por ejemplo en los impuestos a las actividades económicas y la licencia para el desarrollo de actividades económicas, no se puede tener esta última sin haber hecho el pago del impuesto respectivo, pero son dos nociones distintas.

Las patentes de exploración corresponderán a un quincuagésimo de una unidad tributaria mensual, por hectárea; y las patentes de explotación, serán un décimo de una unidad tributaria mensual para sustancias metálicas, y de un trigésimo de una unidad tributaria mensual para sustancias no metálicas. El pago debe realizarse forma anticipada, a beneficio fiscal en el curso del mes de marzo de cada año, en cualquier banco o institución autorizados para recaudar tributos. Asimismo, lo pagado por patente minera de explotación se imputará al Impuesto a la Renta que derive de la actividad minera realizada en la respectiva concesión ${ }^{64}$.

\footnotetext{
${ }^{59}$ ALBURQUENQUE (2001), p. 351.

${ }^{60}$ Ley No18.248, de 1983.

${ }^{61}$ CLAUSSEN (1988), p. 235.

${ }^{62}$ VERGARA (2010), p. 397.

${ }^{63}$ ALBURQUENQUE (2001), p. 351.

${ }^{64}$ Artículo 12, Ley N ${ }^{\circ} 18.097$, de 1982.
} 


\subsubsection{El problema de la naturaleza jurídica de las patentes mineras}

Con respecto a la naturaleza jurídica de estas patentes mineras, también se ha cuestionado si se trata de tributos, o si por el contrario son "derechos" ${ }^{65}$. Y es que el empleo del término "patente" per se, es ya motivo de revisión pues, por una parte si es que se tratase de un tributo, en principio, no se corresponde con ninguno de la tradicional clasificación tripartita, y por otro lado, no son propiamente títulos o licencias para el ejercicio de una actividad económica que es a lo que normalmente se refiere el término patente.

Lo que sí está claro es que se trata de una cantidad de dinero cuyo pago es condición para el mantenimiento del título, por lo que con independencia de cuál sea su naturaleza jurídica, es posible afirmar que están relacionadas con el carácter dominial de las minas, y es por ello que han sido incluidas en esta investigación.

En ese sentido, en el caso de Chile, lo que justifica la exigencia de esta patente no es que el Estado sea o no el "dueño" de las minas sino su afectación. Es en ella donde reside la esencia del dominio público, pues, si las minas han sido afectadas, la entrega, uso y/o aprovechamiento por unos con exclusión o limitación de otros (viéndose limitada la satisfacción del interés público que justificó su afectación), debería encontrar alguna justificación en el ordenamiento jurídico y no podría hacerse a título gratuito a menos que exista también justificación para ello.

Ahora bien, la determinación de su naturaleza no resulta sencilla si se tiene en cuenta que por una parte, la Ley № $19.143^{66}$ dispone expresamente en su Artículo Único, que una cantidad igual al producto de las patentes de amparo de concesiones mineras, "que no constituyen tributos", se distribuirá entre las regiones y comunas del país. Asimismo, si se tiene en cuenta que en la doctrina se ha desechado la idea que se trate de una tasa o de un derecho, alegando que no implica la existencia de una contraprestación por parte del Estado; y también se ha descartado que sea un impuesto, arguyendo que su finalidad no es la de proveer de fondos al fisco sino, la de mantener el régimen de amparo ${ }^{67}$. Algún autor de derecho minero chileno, incluso ha considerado que las patentes mineras no son tributos porque, en rigor constituyen "una carga patrimonial propiamente tal", una "prestación de carácter patrimonial a favor del Estado," de naturaleza real, que tiende indirectamente a obtener el cumplimiento de la obligación que el Artículo 19 numeral 24 de la CPCh impone al titular de la concesión para que desarrolle la actividad necesaria para satisfacer el interés público que justifica su otorgamiento ${ }^{68}$. Así para otro autor se trata de un "fenómeno jurídico especial"69. Pero entonces, ¿Qué es? Y ¿qué legitima al Estado para exigirlas? ¿La respuesta a cuál es su naturaleza jurídica reside únicamente en su finalidad o existen otros elementos que deben considerarse?

Pues bien, en general los tributos son prestaciones patrimoniales de carácter público, que se satisfacen a los entes públicos con la finalidad de contribuir al sostenimiento de los gastos públicos, aunque puede no ser este su único fin, y que gravan un presupuesto de hecho denominado hecho imponible, que en principio, debe revelar algún indicio de capacidad económica fijado en la Ley.

En Chile conforme a la Comisión de Estudio de la Nueva Constitución (CENC), el "tributo" es un término genérico que integra a cualquier impuesto, contribución, arancel, derecho o tasa, es decir, cualquier prestación que los particulares tengan que satisfacer al Estado ${ }^{70}$. Entonces, para un sector de la doctrina chilena, la Constitución ha empleado la expresión tributo, en su Artículo $19 \mathrm{~N}^{\circ} 20$, para englobar toda exacción patrimonial impuesta por la ley a las personas en

\footnotetext{
${ }^{65}$ DEUTSCH y SPIEGEL (2014), p. 54, opinan que las patentes mineras no son impuestos y por lo tanto no es de la competencia del Servicio de Impuestos Internos, órgano de aplicación y fiscalización de los Tributos en Chile.

${ }^{66}$ Ley № 19.143, de 1992, a que se refieren los párrafos $1^{\circ}$ y $2^{\circ}$ del título X del Código de Minería.

${ }^{67}$ LIRA (2007), pp. 188-189.

68 OSSA (2007), p. 505.

${ }^{69}$ ANSALDI (2007), p. 299.

${ }^{70}$ CENC (1978), p. 3115. Sesión N³98, 11 de julio de 1978.
} 
beneficio de nación ${ }^{71}$. O bien, a las obligaciones pecuniarias que la ley impone a las personas para el cumplimiento de los fines de bien común propios del Estado ${ }^{72}$.

Pero tal y como refiere Masbernat ${ }^{73}$, en la doctrina chilena no existe claridad sobre lo que debe entenderse por tributo, y aunque se tiende a defender un supuesto carácter amplio del mismo ${ }^{74}$, en la práctica este ha venido cambiando cada vez más a través de la jurisprudencia que suele ser por demás restrictiva. A este respecto, en opinión del autor, la doctrina ha defendido una tesis a la que cataloga como "falsamente amplia" en la que se incluyen los impuestos, tasas y contribuciones, pero esas categorías a su decir; no son tan amplias, pues no incluyen a todas las posibles figuras tributarias existentes, ya que puede haber subcategorías anómalas que de igual forma se inserten en la categoría tributo.

Por otra parte, la jurisprudencia del Tribunal Constitucional chileno (TCCh) ha venido dejando fuera del estatuto constitucional de los tributos, una serie de figuras que en los hechos constituyen exacciones de riqueza de los ciudadanos impuestas por normas de Derecho Público, lo que le ha llevado en uso de un lenguaje confuso y no técnico al extremo de considerar que el impuesto es la única clase de tributos ${ }^{75}$, y al mismo tiempo a agrupar con un contenido indiferenciado a las tasas, derechos, tarifas y precios $^{76}$.

En este orden de ideas, el TCCh ha llegado a sostener que los tributos, "impuestos o contribuciones" (como si se tratase de lo mismo), son prestaciones pecuniarias exigidas coactivamente por la ley a quienes incurran en los hechos o situaciones que esta grava, con miras a subvenir al funcionamiento del Estado en su conjunto, sin que vayan acompañadas de una contraprestación directa y específica en beneficio del contribuyente. Asimismo, que estos se distinguen de los "derechos" a los que considera iguales al término "tasa", opinando que son prestaciones pecuniarias exigidas del administrado para contribuir a solventar, siquiera parcialmente, el costo que para la Administración Pública representa la prestación de un servicio que le proporciona al erogante o, bien, los gastos en que incurrirá para franquear el uso público de un bien de esa naturaleza cuando el mismo se vea obstaculizado o entorpecido por el disfrute particular de ese bien entregado a un particular por vía de concesión o permiso ${ }^{77}$. Esta decisión deja en evidencia que el TCCh equiparó el término "tributo", a la definición de impuesto; y aunque reconoce algunos de los elementos esenciales del término "tasa", rechaza su naturaleza tributaria, lo que iría en contradicción con la clasificación tripartita y las concepciones que predican la amplitud del concepto de tributo en el país.

Con todo, se comparte lo expuesto por Masbernat para quien desde el punto de vista científico, el concepto de tributo en Chile sí tiene una carácter amplio, pero con un alcance restringido de finalidades, lo que significa que debe entenderse desde una perspectiva que tutele derechos fundamentales, en un esquema de ponderación de finalidades constitucionalmente reconocidas, tales como el bien común o el interés general ${ }^{78}$. También que las clases de tributos no solo deben considerarse vinculadas a impuestos, tasas y contribuciones, sino que deben considerarse igualmente otra clase de figuras anómalas cualquiera sea su

\footnotetext{
${ }^{71}$ FIGUEROA (1985), pp. 26-30. EVANS y EVANS (1997), p. 283.

72 EVANS (2010), p. 94.

73 MASBERNAT (2016), p. 156.

${ }^{74}$ En ese sentido ver por ejemplo a FELIU (2001), p. 355; FERNÁNDEZ (2000), p. 357; lo que es compartido por NAVARRO (2008), p. 78.

${ }^{75}$ Sentencia Tribunal Constitucional, Rol N 1034/2008, de 7 de octubre de 2008. Pero en sentido contrario, la Corte Suprema, ha expresado que "el vocablo tributo fue incorporado en nuestra actual Constitución, en reemplazo de la voz contribuciones o impuestos, de modo que ha de entenderse que comprende, además, las tasas y los demás derechos o cargas semejantes" ( sentencia Corte Suprema, Rol N 16.293, de 28 de enero de 1992). También que "comprende cualquier obligación, aún aquella que nace de un hecho voluntario, quedando comprendida en ella la prestación pecuniaria que el estado exige a quien hace uso actual de ciertos servicios públicos, llámense derechos o tasas" (sentencia Corte Suprema, Rol N³260-2003, de 21 de enero de 2004).

${ }^{76}$ MASBERNAT (2016), p. 156. Al respecto ver entre otras: sentencia del Tribunal Constitucional, Rol N $183 / 1994$, de 17 de mayo de 1994; Rol N²47/1996, de 14 de octubre de 1996; Rol N 1405/2010, de 03 de agosto de 2010.

77 Sentencia del Tribunal Constitucional, Rol N 1034/2008, de 07 de octubre de 2008.

78 MASBERNAT (2016), pp. 156 y 157.
} 
denominación que efectivamente sean tributos por reunir las condiciones de esta categoría general ${ }^{79}$.

Si las patentes mineras son tributos deberían reunir entonces las características propias de tal noción. Y en efecto, concordando con lo expresado por Vergara, es posible afirmar que así es; ello por cuanto se trata de una prestación que, impuesta por ley a los concesionarios mineros, deben satisfacer al Estado a beneficio fiscal que además es usada para contribuir a los gastos públicos, específicamente los regionales y municipales ${ }^{80}$, (Artículo 12 Ley Orgánica Constitucional de Concesiones Mineras) ${ }^{81}$, a lo que debe añadirse que se encuentra fundada en el bien común o el interés general que el dominio público viene a tutelar.

Ahora bien, en opinión del citado autor (a la que se adhiere quien escribe), la razón para que se haya decidido "aclarar" por ley que las patentes mineras no tienen carácter tributario, es que si se expresase abiertamente que las patentes mineras son tributos, el hecho de que los ingresos percibidos a través de ellas sean destinados a sufragar los gastos regionales y municipales, constituye una vulneración a la prohibición constitucional de afectación ${ }^{82}$. En efecto, de forma similar a lo que ocurre con el canon minero peruano, la Ley № 19.143, además de negar el carácter tributario de las patentes, dispone en su Artículo Único, que el producto de las mismas se distribuirá de forma tal que el $50 \%$ se incorpore a la cuota del Fondo Nacional de Desarrollo Regional que anualmente le corresponda, en el Presupuesto Nacional, a la Región donde tenga su oficio el Conservador de Minas en cuyos Registros estén inscritas el acta de mensura o la sentencia constitutiva de las concesiones mineras que den origen a las patentes respectivas; y el otro $50 \%$ restante corresponderá a las Municipalidades de las Comunas en que están ubicadas las concesiones mineras, para ser invertido en obras de desarrollo de la Comuna correspondiente.

Ahora bien, si pese a la negativa legal (que en estricto rigor obedece a una decisión política), las patentes mineras en esencia son tributos, lo siguiente sería preguntarse si pueden encajarse en alguno de los que integran la noción tripartita. Asimismo, si la imposibilidad de ello excluye su naturaleza tributaria. En ese sentido, tal y como se señaló anteriormente, desde el punto de vista científico-jurídico dado el carácter amplio de la noción de "tributo" en Chile, resulta incluso inoficioso tratar de insertar a las patentes mineras en la clasificación tripartita ya que como se indicó, aun tratándose una figura anómala, las clases de tributos no solo deben considerarse vinculadas a impuestos, tasas y contribuciones, sino que deben considerarse igualmente otra clase de figuras cualquiera sea su denominación que efectivamente sean tributos $^{83}$ y las patentes mineras lo son, al menos desde una perspectiva teórica. Las patentes mineras son entonces de "tributos encubiertos", que, habiendo sido establecidos por el Estado, presentan desviaciones con respecto a los ordinarios o normales, lo que les hace insertarse en el fenómeno conocido en el derecho comparado como parafiscalidad ${ }^{84}$.

Los tributos parafiscales, en suma, son afectados a unas finalidades concretas y determinadas, caracterizados por la singularidad de su régimen jurídico, tanto en su nacimiento como en su desarrollo y destino final ${ }^{85}$. La importancia de esta conclusión radica en que, la existencia de la parafiscalidad representa un grave quiebre del Estado de Derecho dondequiera

\footnotetext{
${ }^{79}$ MASBERNAT (2016), pp. 178 y 179.

${ }^{80}$ VERGARA (2010), p. 400.

${ }^{81}$ Ley N¹8.097, de 1982.

${ }^{82}$ El Artículo 19 N 20 de la Constitución Política Chilena, contiene una limitación en cuanto al destino que debe o puede darse a lo recaudado en concepto de tributos, al establecer que los tributos que se recauden, cualquiera que sea su naturaleza, ingresarán al patrimonio de la Nación y no podrán estar afectos a un destino determinado. Sin embargo, como excepción a esta regla, el inciso final de este artículo aclara que la ley podrá autorizar que determinados tributos puedan estar afectados a fines propios de la defensa nacional.

83 MASBERNAT (2016), pp. 178 y 179.

${ }^{84}$ FERREIRO (2010), p. 246. La parafiscalidad entonces puede entenderse como una anormalidad que puede tener diversos grados según los casos y momentos, pero en esencia, siguen siendo tributos. según advierte el autor por medio de la parafiscalidad se crea un sistema independiente del sistema fiscal ordinario. Un sistema que no responde en la medida deseable a principios de legalidad, capacidad y seguridad.

${ }^{85}$ MARTíN y LOZANO (1990), p. 151.
} 
que ella exista. De una parte, porque suponen una clara vulneración de los principios tributarios tradicionales, quebrando, además, todos los principios presupuestarios clásicos: universalidad, no afectación, unidad de caja. De otra, porque quiebra también el principio de seguridad jurídica, toda vez que el ciudadano se ve obligado a pagar unos tributos, sin que disponga de los medios de reacción que son admisibles contra cualquier acto administrativo de liquidación tributaria. Por lo tanto, una reforma tributaria integral en Chile debería corregir esta situación.

\section{Conclusiones}

El reconocimiento de las peculiaridades de la actividad minera ha llevado a incluirlas en la categoría de dominio público o bien, a que se les considere "propiedad pública", lo que ha ocurrido en países como Chile, España y Perú, en los que a pesar de sus diferencias, bajo ciertos límites, el Estado puede imponer cargas a quienes se dediquen a la actividad minera. Uno de los elementos objetivos que se utiliza para ello es el uso o el aprovechamiento del dominio público. Este elemento se utiliza también como fundamento para la imposición de otras cargas sobre las que se suele negar una eventual naturaleza jurídica tributaria, a través de la legislación, doctrina o jurisprudencia. Pero un análisis científico determinará que algunas justificaciones políticas pudieran no influir en su la calificación jurídica como tributo.

Que las minas integren el dominio público, supone (al menos desde el punto de vista científico) que su aprovechamiento por los particulares, quienes se harán titulares de derechos mineros beneficiándose de los mismos, debería ser jurídicamente justificado y no debería hacerse a título gratuito, porque detrás del dominio público hay un interés general que debe ser garantizado. Asimismo, aunque la determinación de la naturaleza jurídica de estas obligaciones o cargas a veces denominadas cánones y regalías resulta compleja (pues en la práctica su uso es indiscriminado); es posible observar su clara vinculación al carácter demanial de las minas, lo que lleva consigo la protección del interés general, del bien común o el fomento de la riqueza nacional.

En algunos casos, como el del Perú, se niega el carácter tributario al sostener que el Derecho de Vigencia es un recurso originario del Estado derivado del carácter patrimonialista de las minas. Así es entendido como una retribución económica que debe pagar el concesionario por el mantenimiento de la concesión minera. En tanto que la Regalía también en Perú, ha sido definida como la contraprestación económica que los sujetos de la actividad minera pagan al Estado por la explotación de los recursos minerales metálicos y no metálicos. Se trataría de una retribución de carácter compensatorio por el usufructo de lo que se extrae, por el uso o aprovechamiento de un bien que, "siendo propiedad de la nación", es concedido al titular de la actividad minera para que pueda obtener el dominio sobre los productos del mismo. En todo caso, con ambas definiciones se quiere negar la naturaleza jurídica tributaria de dichas cargas.

Sin embargo, ese mismo uso o aprovechamiento de un bien del dominio público como lo son las minas, ha llevado en España al establecimiento de una tasa denominada Canon de Superficie de Minas, y aunque allá se acoge una concepción patrimonialista del dominio público (que lo entiende como una propiedad especial), hoy en día resulta innegable la naturaleza jurídica tributaria de dicho canon. En Chile por su parte, pueden vincularse al carácter demanial de las minas las Patentes Mineras (que tampoco están exentas de discusión), sobre las cuales en términos similares a lo que ocurre en Perú, se ha negado por ley y algún sector de la doctrina, su naturaleza jurídica tributaria aunque desde el punto de vista teórico comparte todas las características del género "tributo".

En definitiva, el ambiguo tratamiento legal y conceptual que rodea a las cargas que se exigen en virtud del dominio público de las minas, así como la negativa de su reconocimiento como un tributo se traduce en menos ventajas a los sujetos pasivos de esta obligación, quienes no pueden ampararse en las garantías que ofrecen los principios tributarios ya que se insertan en el mundo de la parafiscalidad. Lo que constituye un grave quiebre del Estado de Derecho al 
suponer una clara vulneración no solo del principio de seguridad jurídica, sino también de los principios tributarios y los principios presupuestarios de universalidad, no afectación, unidad de caja.

La opinión expresada es científica, ya que aunque se entiende que cada ordenamiento jurídico decide en definitiva conforme a sus normas, cuáles figuras quedan dentro del estatuto de los tributos y cuáles no, tales decisiones podrían contar con justificaciones políticas, pero jamás influir en su calificación jurídica, al menos desde el punto de vista teórico, de modo que de cara a una eventual reforma tributaria en Chile, esta situación debiera ser corregida.

Finalmente, a pesar del trato diferenciado que se pueda dar a las figuras que gravan el dominio público en los distintos ordenamientos jurídicos, producto del carácter demanial de las minas, se considera que la naturaleza jurídica de las cargas que se establecen debería ser entendida en un ámbito de potestades y no de propiedad, lo que puede traer como consecuencia que aunque no se hace, debería reconocerse su carácter tributario, sobre todo en aquellos casos en los que el mismo es evidente como ocurre por ejemplo con la regalía minera peruana y las patentes mineras chilenas.

\section{BiBLIOGRAFÍA CITADA}

Alburquenque Troncoco, Winston (2001): "Las Minas y las Aguas en la Constitución de 1980", en: Revista Chilena de Derecho (28, № 2), pp. 345-354.

Alessandri Rodríguez, Arturo y Somarriva UndurRaga, Manuel (1974): Curso de derecho Civil, los bienes y los derechos reales (Santiago, Editorial Nascimento).

Alvarez-Gendín, SABINo (1956): El dominio público. Su naturaleza jurídica (Barcelona, Bosch).

Ansaldi Domínguez, CARmen (2007): Curso de Derecho Minero, 2a edición (Santiago, Editorial Metropolitana).

CAWOOd, F.T. y MACFARLANe, A.S. (2003): "The Mineral and Petroleum Royalty Bill-Report to National Treasury", en: The Journal of the South African Institute of Mining and Metallurgy. South Africa, South African Institute of Mining and Metallurgy (Vol. 103), pp. 213-232.

CAWOOD, F.T. (2004): Will the New South African Mineral and Petroleum Royalty Bill Attract o Deter Investment? Research paper. Centre for Energy, Petroleum and Mineral Law and Policy (Scotland, University of Dundee).

Claro SolAR, LUIS (1979): Derecho Civil Chileno (Santiago, Editorial Jurídica de Chile), tomo IV.

Claussen Calvo, Carlos (1988): "Análisis del sistema de amparo de la propiedad minera", en: Revista Chilena de Derecho (Vol. 15, № 2-3), pp. 159-187.

De ARCENEGUI, ISIDRo (2002): Derecho Minero (Madrid, Civitas).

De LA TORRE SALAS, MARIella (2005): "Algunas consideraciones sobre las regalías mineras", en: Revista del Instituto Peruano de Derecho Tributario (№ 43), pp. 61-78.

Deutsch Spiegel, Pedro y Orellana Pavón, Juan (2014): Tributación de la Minería en Chile (Santiago, Thomson Reuters).

Enos AguirRe, Rafael (2005): Derecho de Áridos (Santiago, Lexis Nexis).

Evans De La Cuadra, EnRique y Evans Espiñeira, Eugenio (1997): Los Tributos ante la Constitución (Santiago, Editorial Jurídica de Chile).

Evans De La Cuadra, EnRIQue (1999): Los Derechos Constitucionales, 2a edición (Santiago, Editorial Jurídica de Chile), tomo III. 
EVANS EsPINEIRA, Eugenio (2010): Los tributos en la Constitución (Santiago, Editorial Jurídica de Chile).

Feliú Segovia, Olga (2001): “Los tributos en la Constitución”, en: Navarro Beltrán, Enrique (Ed.), 20 años de la Constitución Chilena 1981-2001 (Santiago, Editorial Jurídica Conosur Ltda.), pp. 331-357.

FERMANDOIS VöHRINGER, ARTURo (2010): Derecho Constitucional Económico, 2ạ edición (Santiago, Ediciones Universidad Católica de Chile), tomos I y II.

FERNÁNDEZ AMOR, JOSÉ Y MASBERNAT MUNOZ, PATRICIO (2011): “El principio de capacidad económica en la jurisprudencia tributaria comparada de Chile y España", en: Revista de Derecho de la Pontificia Universidad Católica de Valparaíso (XXXVII), pp. 567 - 593.

FernÁNDEZ González, Miguel Ángel (2000): "Principios constitucionales de proporcionalidad y justicia en materia tributaria", en: Revista Chilena de Derecho (Vol. 27, № 2), pp. 357-371.

FerReiro LAPATZA, José JUAN (2010): Instituciones de derecho financiero y tributario (Madrid, Marcial Pons).

Figueroa ValdÉs, JuAn EdUARdo (1985): Las Garantías Constitucionales del Contribuyente en la Constitución Política de 1980 (Santiago, Editorial Jurídica de Chile).

GALÁN SÁNCHEZ, ROSA (2009): “Los bienes públicos y su régimen tributario”, en: González García, Julio (Coord.), Derecho de los bienes públicos, 2ª edición (Valencia, Tirant Lo Blanch), pp. 337377.

Gallego AnABitarte, Alfredo (1982): "Los cuadros del Museo del Prado (I). Reflexiones histórico y dogmático-jurídicas con ocasión del artículo 132 (y 133.1) de la Constitución española de 1978", en: Presidencia del Gobierno (Ed.), Administración y Constitución. Estudios en homenaje al profesor Mesa Moles (Madrid, Presidencia del Gobierno), pp. 227-309.

(1986): "El derecho español de aguas en la historia y ante el derecho comparado", en: Gallego Anabitarte, Alfredo; Menéndez Rexach, Ángel y Díaz Lema, José Manuel (Coords.), El derecho de aguas en España (Madrid, Ministerio de Obras Públicas y Urbanismo, Centro de Publicaciones), pp. 13-420.

García De Enterría, EduARdo y Escalante, José ANTONio (1982): Legislación Administrativa, 4ạ edición (Madrid, Civitas).

García De Enterría, Eduardo (1984-1985): Apuntes de Derecho Administrativo, 3ạ edición (Madrid, Civitas).

(1998): Dos estudios sobre la usucapión en derecho administrativo, 3a edición (Madrid, Civitas).

García NovoA, CÉSAR (1997): "La Sentencia del Tribunal Constitucional 185/1995 de 14 de diciembre y su influencia sobre la potestad tarifaria", en: Revista Técnica Tributaria (№ 36), pp. 53-76.

(2012): El concepto de tributo (Madrid, Marcial Pons).

GARCíA SCHRECK, MARCIAL (2004): “El problema tributario en la industria minera. Las regalías en el ojo de la tormenta", en: lus et Veritas: Revista de la Asociación lus et Veritas (№ 28), pp. 245252.

GARRIDO FAlLA, FernANDo (1962): "Sobre el régimen del dominio público", en: Problemática de la ciencia del derecho. Estudios en homenaje al profesor José María Pi y Suñer (Barcelona, Bosch), pp. 303-340. 
(2002): Tratado de derecho administrativo II. Parte general: conclusión, 11ạ edición (Madrid, Tecnos).

González García, Julıo (1998): La Titularidad de los Bienes del Dominio Público (Madrid, Marcial Pons).

(2009): "Notas sobre el régimen general del dominio público", en: González García, Julio (Dir.), Derecho de los bienes públicos, 2a edición (Valencia, Tirant Lo Blanch Editores), pp. 67-108.

GuAitA, AuRelio (1956): "Le domaine public en Espagne", EN: Revue Internationale des Sciences Administratives (№ 22), pp. 121-140.

(1986): Derecho Administrativo. Aguas, montes, minas (Madrid, Civitas).

Guerrero Del Río, Roberto (1998): “Consideraciones en torno al orden público económico y los impuestos manifiestamente desproporcionados e injustos", en: Revista de Derecho de la Universidad Finis Terrae (Año 2), pp. 107-116.

GuJ, Pietro (2012): "Regalías mineras y otros impuestos específicos a la minería", en: International Mining for Development Centre Mining for Development: Guide to Australian Practice. Disponibe en: https://www.im4dc.org/wpcontent/uploads/2012/01/UWA_1833_Paper-1_Spanish-version_Mineralroyalities-and-othermining-specific-taxes.pdf [visitado el 13 de septiembre de 2015].

JARACH, DINO (2003): Finanzas Públicas y Derecho Tributario (Buenos Aires, Abeledo Perrot).

Landa Arroyo, YURI (2017): "Renta extractiva y minería del cobre en el Perú", en: Revista Problemas del Desarrollo (Vol. 48, № 189), pp. 141-168.

LiRa Ovalle, SAmuel (2012): Curso de Derecho de Minería, 7ạ edición (Santiago, Editorial Jurídica de Chile).

Manco Zanconetti, JoRge Eusebio (2002): "Canon Minero: Problemas y Posibilidades con la Descentralización", en: Revista de la Facultad de Ciencia Económicas (Año VII, № 21), pp. 23-46.

Martín Queralt, Juan y Lozano Serrano, Carmelo (1990): Curso de Derecho Financiero y Tributario (Madrid, Tecnos).

Martín Queralt, Juan; lozano Serrano, Carmelo; Tejerizo lópez, José y Casado Ollero, Gabriel (2010): Curso de Derecho Financiero y Tributario, 21a edición (Madrid, Tecnos).

MARTínez LAFUENTE, ANTONIO (2011): La tasa por utilización o aprovechamiento especial del dominio público en la Doctrina de los Tribunales de Justicia (Madrid, Colegio de Registradores de la Propiedad y Mercantiles de España).

Masbernat Munoz, Patricio (2013): "Reglas y principios de justicia tributaria: aportes del Derecho Español al Derecho Comparado", en: Revista de Derecho (Año 20, № 1), pp. 155-191.

(2016): "El concepto de tributo y sus finalidades u objetivos", en: Revista Tributária e de Finanças Públicas (Ano 24, 129, julho-agosto), pp. 155-192.

Morillo-Velarde Pérez, José (1992): Dominio Público. Estudios Trivium, Administrativo (Madrid, Editorial Trivium).

Munoz Del CASTILLo, José LUIS (2006): "El canon de superficie de minas y las revisiones de las tasas en las leyes de presupuestos", en: Revista Nueva Fiscalidad (№ 2), pp. 9-53.

NAVARRo Beltrán, EnRIQUe (2008): "Notas sobre principios de Derecho Constitucional Tributario", en: Revista de Derecho Público (№ 70), pp. 77-87. 
ORÉ CHÁVEZ, IVÁN (2008): “Canon minero y poder demanial del Estado", en: Revista Derecho y Cambio Social (№ 15 - Año $\quad$ V). Disponible en: https://www.derechoycambiosocial.com/revista015/canon\%20minero.htm [visitado el 13 de septiembre de 2016].

OSSA BULNES, JUAN LUIS (2012): Tratado de derecho de minería, 5a edición (Santiago, Editorial Jurídica de Chile).

Otto, James; Guj, Pietro; Andrews, Craig; Tilton, John; Cawood, Fred; Stermole, Frank; SteRMOLE, JOHN Y DOGGetT, MiChAel (2006): "Mining Royalties: a global study of their impact on investors, government, and civil society". Disponible en: https://openknowledge.worldbank.org/handle/10986/7105 [visitado el 13 de septiembre de 2015].

Parejo Alfonso, luciano (1983): "Dominio público: un ensayo de reconstrucción de su teoría general”, en: Revista de Administración Pública (№ 100-102), pp. 2379-2422.

(2011): Lecciones de Derecho Administrativo, 4a edición (Valencia, Tirant Lo Blanch).

PARejo GamiR, Roberto (1975): Protección registral y dominio público (Madrid, Editorial Revista de Derecho Privado).

Parejo Gamir, Roberto y Rodríguez Oliver, José María (1976): Lecciones de dominio público (Madrid, ICAI).

Pozuelo Yvancos, EnRIQUe, (1986): “El Canon de Superficie de Minas”, en: Crónica Tributaria (№ 56), pp.169-172.

PreCht PizARRo, JoRge (1983): "Naturaleza jurídica del dominio del Estado sobre las minas y de la concesión minera en la Constitución de 1980", en: Revista Chilena De Derecho (№ 10, 3), pp. 727-779.

Ribera Neumann, Teodoro (2000): "La potestad tributaria del Estado", en: Revista de Derecho Público ( $\left.\mathrm{N}^{\circ} 62\right)$, pp. 22-31.

RodríGuez García, CARLOS (1992): Una nueva sistematización jurídica de las propiedades especiales (Madrid, Editorial Dykinson).

RODRíGuez LOSADA, SORAYA (2015): "Análisis del canon eólico de Galicia al hilo de las últimas resoluciones del Tribunal Superior de Justicia”, en: Dereito, Revista Jurídica (Vol. 24, № 1), pp. 115-128.

Rodríguez MARIÁtegui CANNY, LUIS Y TORRES ZARIQUIEY, CARLA (2010): "Régimen de Caducidad de las Concesiones Mineras", en: Revista Derecho \& Sociedad ( $\left.N^{\circ} 35\right)$, pp. 42-48.

Rosa Moreno, Juan (2009): "Regímenes dominiales específicos. Propiedades Especiales. Dominio Hidráulico", en: Parejo Alfonso, Luciano (Dir.), Derecho de los Bienes Públicos (Navarra, Thomson Reuters Aranzadi), tomo III, pp. 341-390.

Ruíz BouRgeols, Julio (1942): Instituciones de Derecho de Minería Chileno (Santiago de Chile, Editorial Nascimento), tomo I.

SÁEZ-GodoY, LEOPOLDo (2006): “Canon, regalía y royalty en el español de Chile", en: Estudios filológicos (№ 41), pp. 251-265.

Vergara Blanco, Alejandro (1990): "Teoría del Dominio Público y Afectación Minera", en: Revista Chilena de Derecho (Vol. 17), pp. 135-159.

(1992): Principios y sistema del derecho minero: estudio histórico-dogmático (Santiago, Editorial Jurídica de Chile). 
(2001): "Sobre la irreal propiedad estatal minera", en: III Jornadas Chilenas de Derecho de Minería, Serie Seminarios (№ 13), pp. 213-216.

(2010): Instituciones de Derecho Minero (Santiago, Abeledo Perrot - Legal Publishing).

(2014): "La Contemporánea Regulación de la Minería en Chile. Crítica a la Teorías Tradicionales del Dominio Estatal de las Minas", en: Derecho Administrativo. Revista de Doctrina, Jurisprudencia, Legislación y Práctica (N 93), pp. 633-654.

VILDÓSOLA FUENZALIDA, JULIO (1999): El dominio minero y el sistema concesional en América Latina y el Caribe (Caracas, OLAMI).

ZegarRa VílCheZ, JUAN CARLOS (2014): "Principios de imposición en la actividad minera: a propósito de los nuevos gravámenes a la minería en el Perú", en: Revista del Instituto Peruano de Derecho Tributario (№ 57), pp. 155-214.

Zuzunaga, Fernando (2011): “Tributación de la explotación minera y petrolífera en el Perú", en: III Encuentro Regional Latinoamericano de Tributación Internacional IFA 2011, realizado en Bogotá, Colombia en mayo de 2011. Disponible en: http://www.ifacolombia.co/ifacolombia/encuentro/memorias_ifa.php. [visitado el 01 de agosto de 2016].

\section{JURISPRUDENCIA CITADA}

CHILE

REQUERIMIENTO DE INAPLICABILIDAD POR INCONSTITUCIONALIDAD EN CONTRA DE LA LEY DE RENTAS MUNICIPALES INTERPUESTO POR COMPAÑÍA de TELÉFONOS DE CHILE CONTRA MUNICIPALIDAD DE VILLA ALEMANA (1992): Corte Suprema de Chile 28 enero 1992 (acción de inaplicabilidad por inconstitucionalidad), Rol № 16293-1992, en: Revista de Derecho y Jurisprudencia 89, 1992, p. 11.

REQUERIMIENTO FORMULADO POR DIVERSOS DIPUTADOS PARA QUE EL TRIBUNAL DECLARE LA INCONSTITUCIONALIDAD DEL DECRETO SUPREMO № 434, DE 20 DE DICIEMBRE DE 1993, PUBLICADO EN EL DIARIO OFICIAL DE 13 DE ENERO DEL AÑO EN CURSO, QUE MODIFICA TARIFAS EN DETERMINADAS PLAZAS DE PEAJE,

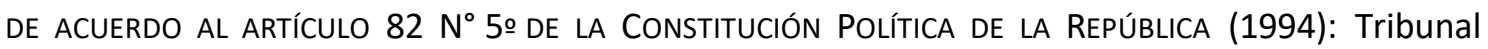
Constitucional 17 mayo 1994 (requerimiento de inconstitucionalidad), Rol № 183-1994, en: https://www.tribunalconstitucional.cl/ver2.php?id=433 [visitado el 22 de enero de 2018].

ReQuerimiento SENADORES RESPECTO DE PROYECTO dE LEY QUE MOdERNIZA EL SERVICIO NACIONAL DE ADUANAS (1996): Tribunal Constitucional 14 octubre 1996 (requerimiento de inconstitucionalidad), Rol $\mathrm{N}^{\circ}$ 247-1996, en: http://www.tribunalconstitucional. $\mathrm{cl} / \mathrm{wp} /$ expedientes?rol=247-96 [visitado el 23 de enero de 2018].

REQUERIMIENTO DE INAPLICABILIDAD POR INCONSTITUCIONALIDAD (2004): Corte Suprema de Chile 21 enero 2004 (acción de inaplicabilidad por inconstitucionalidad), Rol № 3260-2003.

REQUERIMIENTO DE INAPLICABILIDAD POR INCONSTITUCIONALIDAD DEL ARTíCULO 42 DEL DECRETO LEY N 3.063, SOBRE RENTAS MUNICIPALES (2008): Tribunal Constitucional 07 octubre 2008 (requerimiento de inaplicabilidad por inconstitucionalidad), Rol № 1034-2008, en: www.tribunalconstitucional.cl/wp/desent.php?id=1034 [visitado el 25 de enero de 2018].

REQUERIMIENTO DE INAPLICABILIDAD POR INCONSTITUCIONALIDAD DE ABUFRUT LIMITADA Y OTRAS RESPECTO DE LOS ARTí́CULOS 7음 LA LEY № 18.196 Y 7ㅇ, LETRA Ñ), DE LA LEY № 18.755 EN LOS AUTOS ROL № 8325-2009 del SÉptimo Juzgado CIVIL de SANTIAgo (2010): Tribunal Constitucional 3 agosto 2010 (requerimiento de inaplicabilidad por inconstitucionalidad), Rol № 1405-2010, en: https://www.tribunalconstitucional.cl/ver2.php?id=1478 [visitado el 25 de enero de 2018]. 
ESPAÑA

TRibunal Constitucional (1995): Sentencia Nº185/1995, 14 de diciembre (BOE núm. 11, de 12 de enero de 1996) en: http://hj.tribunalconstitucional.es/es-ES/Resolucion/Show/3039 [visitado el 25 de enero de 2018].

Tribunal Supremo, Sala De lo Contencioso Administrativo (Tercera), sentencia Nº 1358/2009, 12 de febrero de 2009, en: http://www.poderjudicial.es/search/documento/TS/4504995/tributario/20090408 [visitado el 25 de enero de 2018].

Perú

Tribunal Constitucional Del Perú (2005): Sentencia del Pleno Jurisdiccional Número 0048-2004$\mathrm{PI}-\mathrm{TC}$, de fecha 1 de abril (demanda de inconstitucionalidad interpuesta por José Miguel Morales Dasso, en representación de más de cinco mil ciudadanos, contra los artículos $10,2^{\circ}, 3^{\circ}, 4^{\circ} \mathrm{Y}^{\circ}$ de la Ley No 28258 -Ley de Regalía Minera - sus modificatorias y las demás normas que sean materia de la causa) en: https://tc.gob.pe/jurisprudencia/2005/00048-2004-Al.pdf [visitado el 25 de enero de 2018].

\section{NORMAS JURÍDICAS CITADAS}

CHILE

DeCreto Supremo N 100, Constitución Política de la República de Chile. Diario Oficial, 22 de septiembre de 2005. En relación a ella también: COMISIÓN DE ESTUDIO DE LA NUEVA CONSTITUCIÓN (CENC). Sesión N³98, 11 de julio de 1978.

LEY N 18.097, Orgánica Constitucional de Concesiones Mineras. Diario Oficial, 21 de enero de 1982.

Ley Nº 18.248, Código de Minería. Diario Oficial, 14 de Octubre de 1983.

LEY $N^{\circ} 19.143$, que establece la distribución de los ingresos provenientes de las patentes de amparo de concesiones mineras, a que se refieren los párrafos $1^{\circ}$ y $2^{\circ}$ del título $\mathrm{X}$ del Código de Minería. Diario Oficial, 17 de junio de 1992.

DECRETO CON FUERZA DE LEY NúMERo 1, que fija el texto refundido, coordinado y sistematizado del Código Civil, Diario Oficial, 30 de mayo de 2000.

ESPAÑA

CONSTITUCIÓN ESPAÑola, 1978. Boletín Oficial del Estado Número 311, 29 de diciembre de 1978.

DECRETO N 3059/1966, Texto Refundido de Tasas Fiscales. Boletín Oficial del Estado Número 302, 19 de diciembre de 1966.

LEY Nº 6/1977, de fomento de la minería. Boletín Oficial del Estado, 8 de enero de 1977.

LEY N54/1980, de modificación de la Ley 22/1973, de Minas, con especial atención a los recursos minerales energéticos. Boletín Oficial del Estado Número 280, 5 de noviembre de 1980.

LEY № 8/1989, de Tasas y Precios Públicos. Boletín Oficial del Estado Número 90, 13 de abril de 1989.

LEY N $12 / 2001$, de tasas y precios públicos de la Comunidad de Castilla y León. Boletín Oficial del Estado Número 15, 17 de enero de 2002. 
LEY N58/2003, General Tributaria. Boletín Oficial del Estado Número 302, 18 de diciembre de 2003.

LEY N ${ }^{\circ} 62 / 2003$, de medidas fiscales, administrativas y del orden social. Boletín Oficial del Estado Número 313, 31 de diciembre de 2003.

LEY $\mathrm{N}^{\circ} 12 / 2007$, por la que se modifica la Ley 34/1998, de 7 de octubre, del Sector de Hidrocarburos, con el fin de adaptarla a lo dispuesto en la Directiva 2003/55/CE del Parlamento Europeo y del Consejo, de 26 de junio de 2003, sobre normas comunes para el mercado interior del gas natural. Boletín Oficial del Estado Número 158, 3 de julio de 2007.

Ley del Parlamento de Galicia Nº 8/2009. Diario Oficial de Galicia, 29 de diciembre de 2009.

REAL DECRETO N 1167/1978, por el que se desarrolla el título III, capítulo II, de la Ley 6/1977, de 4 de enero, de Fomento de la Minería. Boletín Oficial del Estado Número 33, 5 de junio de 1978.

REAL DECRETO N 939/2005, por el que se aprueba el Reglamento General de Recaudación. Boletín Oficial del Estado Número 210, 2 de septiembre de 2005.

PERÚ

Constitución Política del Perú. 31 de diciembre de 1993.

DeCRETO SUPREMO № 014-92-EM, de Ley General de Minería. 4 de junio de 1992.

DECRETO LEgISLATIVO №674. 27 de septiembre de 1991.

LEY № 27.506, DE CANON. 10 de julio de 2001.

LEY № 28.258, DE REgALía MINERA. 23 de junio de 2004.

LEY № 29.788, que modifica la Ley 28258, Ley de Regalía Minera. 28 de septiembre de 2011. 